\title{
Structural Performance Evaluation of a Precast PSC Curved Girder Bridge Constructed Using Multi-Tasking Formwork
}

\author{
Sung-Jae Kim ${ }^{1)}$, Jang-Ho Jay $\mathrm{Kim}^{1), *}{ }^{\mathbb{0}}$, Seong-Tae $\mathrm{Yi}^{2)}$, Norhazilan Bin Md Noor ${ }^{3)}$, \\ and Sung-Chul Kim ${ }^{1)}$
}

(Received March 28, 2016, Accepted June 23, 2016, Published online July 14, 2016)

\begin{abstract}
Recently, advanced transit systems are being constructed to reduce traffic congestions in metropolitan areas. For these projects, curved bridges with various curvatures are required. Many curved bridges in the past were constructed using aesthetically unpleasant straight beams with curved slabs or expensive curved steel box girders with curved slabs. Therefore, many recent studies have been performed to develop less expensive and very safe precast prestressed concrete (PSC) curved girder. One method of reducing the construction cost of a PSC curved girder is to use a reusable formwork that can easily be adjusted to change the curvature and length of a girder. A reusable and curvature/dimension adjustable formwork called Multi-tasking formwork is developed for constructing efficient precast PSC curved girders. With the Multi-tasking formwork, two $40 \mathrm{~m}$ precast PSC box girders with different curvatures were constructed to build a two-girder curved bridge for a static flexural test to evaluate its safety and serviceability performance. The static flexural test results showed that the initial cracking load was $1400 \mathrm{kN}$, exceeding the design cracking load of $450 \mathrm{kN}$. Also, the code allowed deflection of $50 \mathrm{~mm}$ occurred at a load of $1800 \mathrm{kN}$, verifying the safety and serviceability of the precast PSC curved bridge constructed using the multi-tasking formwork.
\end{abstract}

Keywords: curved bridge, precast PSC curved girder, multi-tasking formwork, structural performance evaluation, structural safety and serviceability.

\section{Introduction}

Elevated roads and expressways are mandated in metropolitan areas to ease traffic congestions. Particularly, the usage of curved bridges is inevitable, as bridge configurations must conform to the road alignment to ensure a smooth traffic flow. In fact, the partial or global configuration of a curved section of a girder is designed based on the road alignment. Generally, a curved bridge is designed and constructed as one of three types: (a) straight girders with a curved deck, (b) straight girders and decks used to set up a curved configuration, and (c) curved steel box girders with a curved deck. The type with a straight girders and a curved deck was commonly used for the construction of concrete curved bridges until the 1960s for its design and construction simplicity. However, this type of curved bridge would

\footnotetext{
${ }^{1)}$ School of Civil and Environmental Engineering, Yonsei University, Seoul 03722, Korea.

*Corresponding Author; E-mail: jjhkim@yonsei.ac.kr

${ }^{2)}$ Department of Civil and Environmental Engineering, Inha Technical College, Inchon 22212, Korea.

${ }^{3)}$ Department of Structures and Materials, Faculty of Civil Engineering, Universiti Teknologi Malaysia, 81310 Skudai Johor, Malaysia.
}

Copyright ( $\odot$ The Author(s) 2016. This article is published with open access at Springerlink.com require considerably more substructure construction to sufficiently support a curved deck layout using straight beams, leading to an increase in the overall construction cost (Schmitt 1966; Nakai and Yoo 1988; Suros and Chu 1991). Thus, recent studies on cost-friendly curved girder construction methods have been pursued actively. Early research focused on using a steel box girder as the main girder in a curved bridge, which would provide superior flexural, shear, and torsional capacities. However, steel box girders are extremely expensive and require continuous maintenance to avoid corrosion problem. In order to construct less expensive curved bridges, studies on I-section steel girder for curved bridge application have also been conducted (Lin and Yoda 2010; Zhang et al. 2005; Zureick and Naqib 1999; McElwain and Laman 2000; Linzell et al. 2004).

Although the I-beam steel girder has been broadly used in the construction of curved bridges throughput the world due to the design simplicity, installing this type of girder on-site is difficult. A curved I-shaped girder has an open crosssection with a low torsional strength due to the use of a thin web section, which can cause large axial rotation and lateral deflection. In order to reduce the rotation and deflection, lateral or temporary bracing is required during the installation process (Dong and Sause 2010). A steel box girder with an enclosed cross-section has excellent torsion capacity (Lin and Yoda 2010), but it requires high initial construction as well as long-term maintenance costs. (Lin and Yoda 2010). Therefore, a cost-efficient type of curved bridge that requires 
less maintenance was sought by the bridge industry in Korea. A precast PSC curved girder was proposed as an alternative girder type (Amorn et al. 2008). A curved beam was first proposed by Vlasov in 1946 with the introduction of the governing equations pertaining to the behavior of a curved beam with an open cross-section. In the late 1960s and early 1970s, design and analysis studies on curved beams for practical applications were conducted by Morris (1968) and Yoo et al. (1974). In Korea, based on curved beam theories, a frame analysis was conducted for the construction stage of a PSC curved bridge. Given that a 3D simulation of a PSC curved bridge is a difficult task, a modified frame analysis with better applicability to the design was used. However, due to the significant difference between the inner and outer stress and strain results of the curved section from the frame analysis, new designs and analyses of curved PSC bridges considering torsional effect were conducted using 3D nonlinear finite element analyses. In the USA and Japan, design specifications and standards for curved bridges were published in the "AASHTO: Guide Specification for Horizontally Curved Highway Bridges” and the "Meishin Expressway Association: Guidelines for the Design of Horizontally Curved Girder Bridges” reports, respectively. In addition, the design standards for concrete curved bridges can be found in Report 620 published by National Cooperative Highway Research Program. In Korea, studies of economical designs and construction methods for two I-steel and prestressed concrete (PSC) box-girder curved bridges were conducted. However, the increased construction cost due to the varying curvature of the girder had to be mitigated to be feasible for actual construction projects. Therefore, even now, bridge engineers and designers continue in their efforts to find technologies, which allow reductions in the constriction cost of concrete curved bridges. Then, the optimal design of the cross-section as well as performance verification assessments is achieved through structural simulations and experimentation. The objective of this study is to construct a precast PSC curved girder with a hollow cross-section using the Multi-tasking formwork with flexural, shear, and torsional capacities that exceed the code requirements

\section{Multi-Tasking Formwork}

The steel box-girder bridge type is widely used in the construction of curved bridges, because a curved configuration is easily attainable. However, this type incurs a high initial construction cost while requiring continuous maintenance works such as painting. Attempts have been made to reduce the construction cost of a concrete curved bridge, but the difficulty and costs associated with the construction of the formwork for various radii of curvature of curved girder put an end to these attempts. Building forms for all of the different girder curvatures would drive up the cost, making it

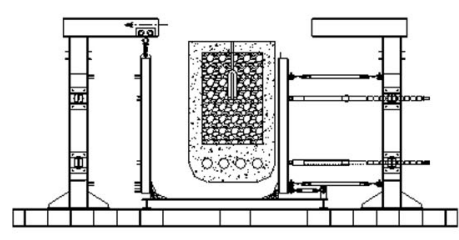

(a)
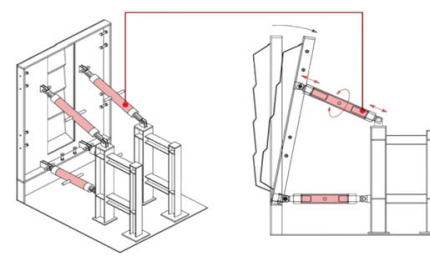

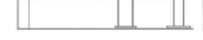

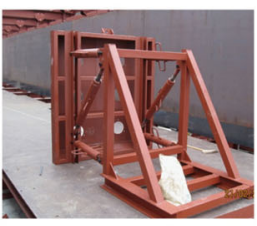

(b)

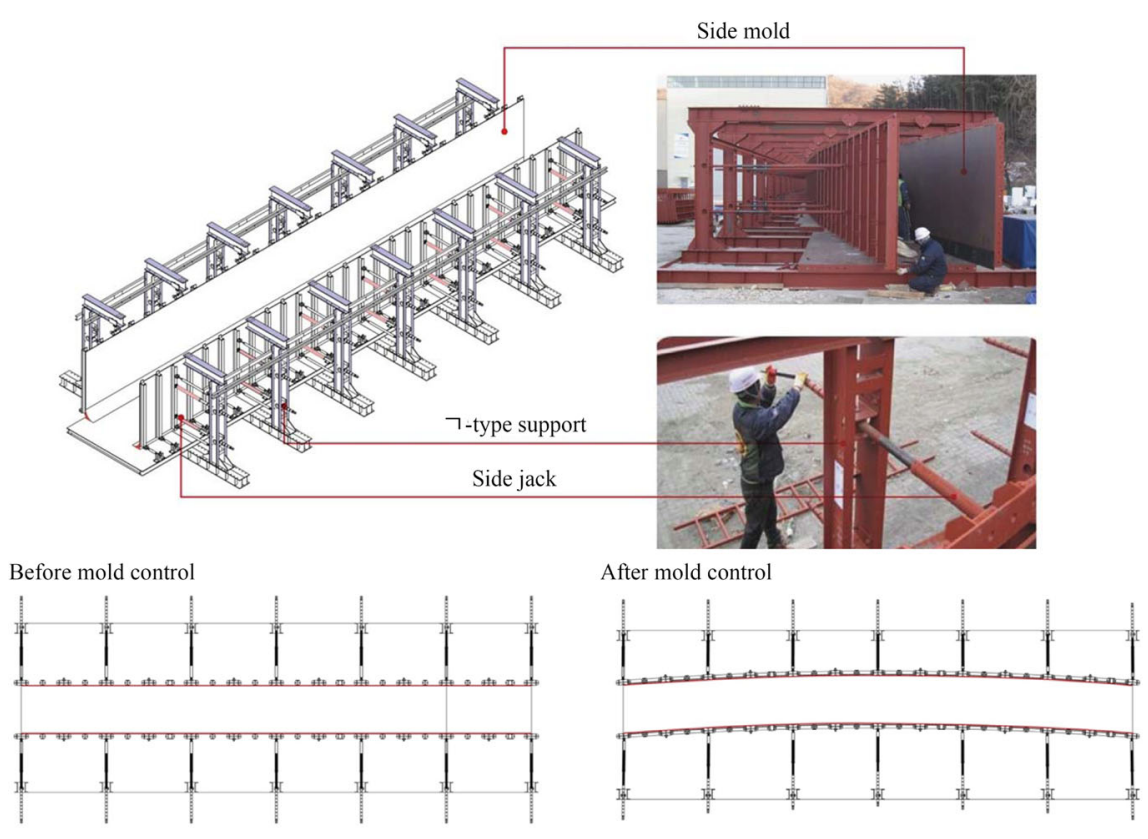

(c)

Fig. 1 Multi-tasking formwork for a curved bridge: a Side view of mold, b end form, $\mathbf{c}$ form control. 


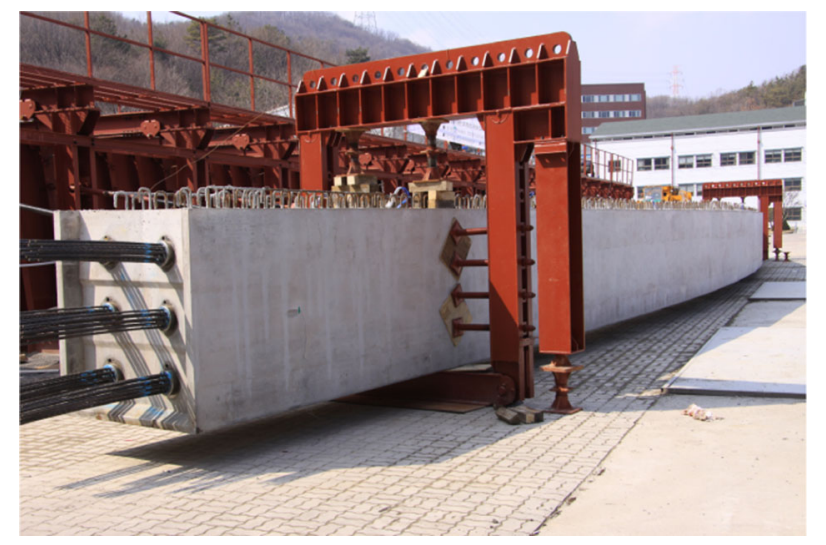

Fig. 2 Lift device for preventing over-turning rotation of a curved girder. more expensive than the initial construction cost of steel box curved girder.

In order to solve this problem, a mold system called a 'Smart Mold' was developed. In this mold, several steel plates are used to set up the side and bottom surfaces of the mold to be used for the construction of a curved girder. The adjustments of the curvatures and dimensions for the construction of curved girders are made using screw jacks and frames attached to exterior of the side walls. In addition, Smart Mold can be recycled, because it consists of continuous steel plates and frames that can be reused for different girder configurations. As shown in Fig. 1, Smart Mold is made up of support jacks, side and bottom steel plates, position-adjustable end cap frames, and adjustable fixture frames. The jacks on both sides of the mold are adjusted to

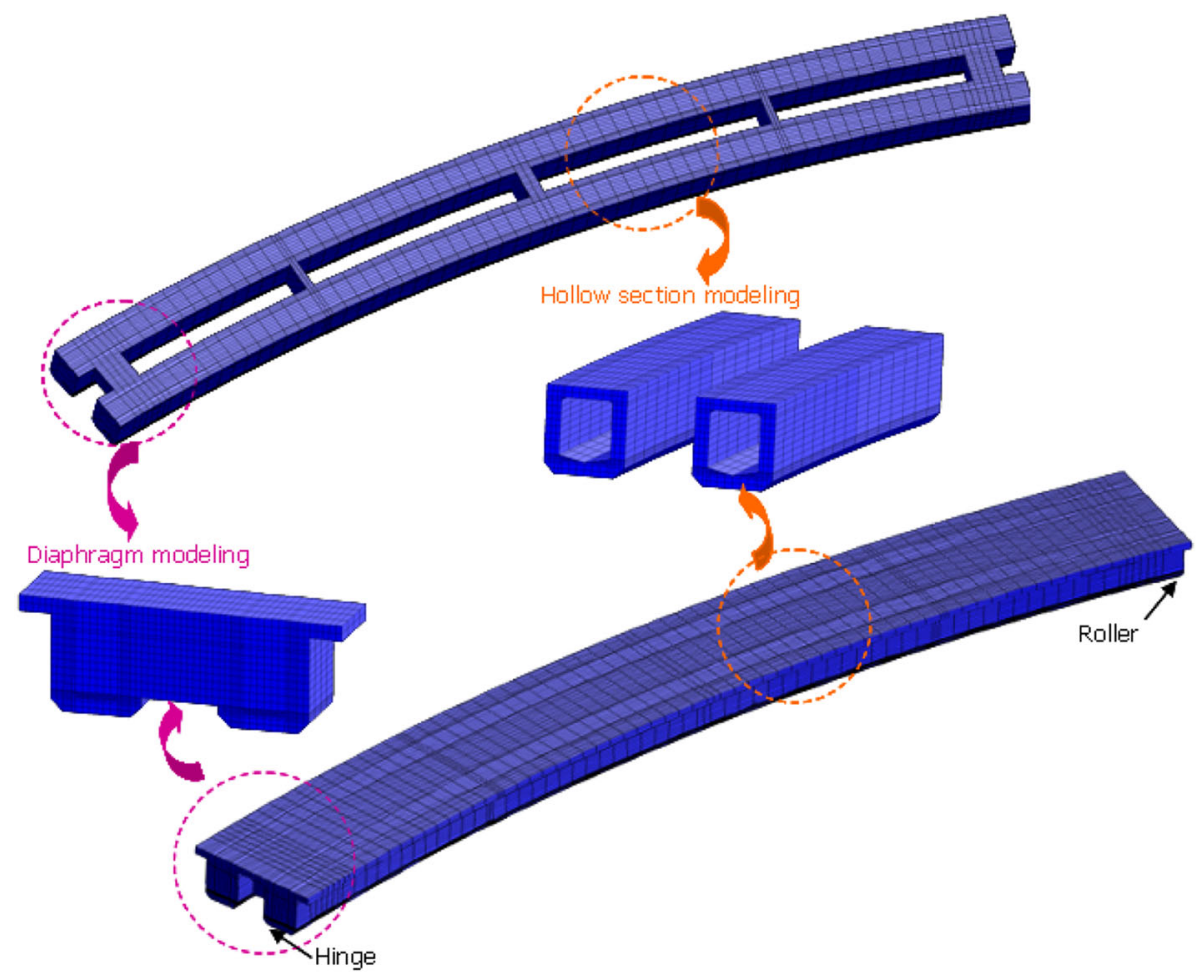

(a)
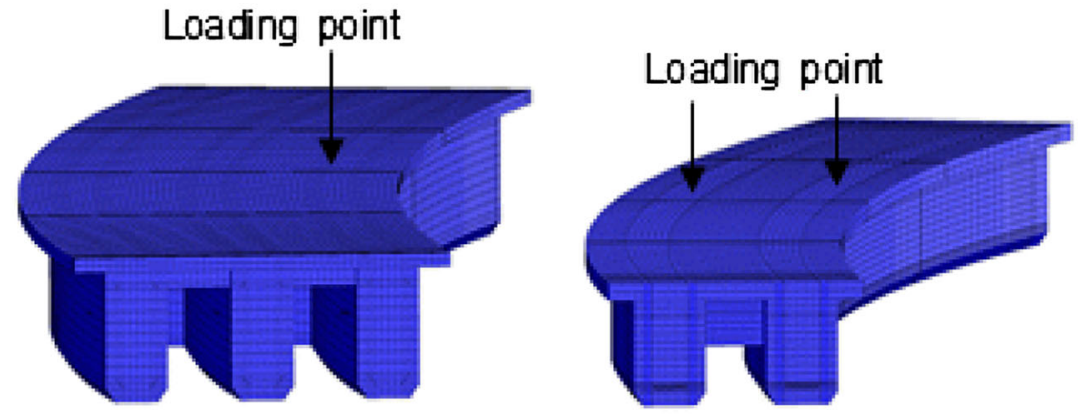

(b)

Fig. 3 FE model of a PSC curved bridge: a Detailed modeling of $40 \mathrm{~m}$ two-girder curved bridge, b $50 \mathrm{~m}$ three-girder and $40 \mathrm{~m}$ twogirder curved bridges. 
Table 1 Parameters used in the FE Simulation.

\begin{tabular}{c|c|c}
\hline Case & Variables & Contents \\
\hline \hline 1 & The number of girders & $\begin{array}{c}2 \text { girder-length } 40 \mathrm{~m} \\
\text { Vs } 3 \text { girder-length } 50 \mathrm{~m}\end{array}$ \\
\hline 2 & Loading point & $\begin{array}{c}\text { Inner loading.(G2) } \\
\text { Vs Outer loading (G1) }\end{array}$ \\
\cline { 1 - 3 } & & $150 \mathrm{~cm}, 155 \mathrm{~cm}, 160 \mathrm{~cm}$ \\
\hline 4 & Sectional height & G1,2 $100 \%, 110 \%, 120 \%, 130 \%$ \\
\cline { 1 - 2 } & Prestressing force & G2 $100 \%, 110 \%, 120 \%$ \\
$(\mathrm{G} 1100 \% \mathrm{fixed})$
\end{tabular}

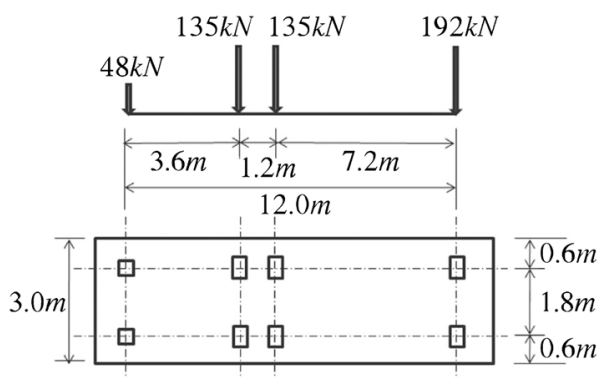

Fig. 4 Korean KL-510 live loading.

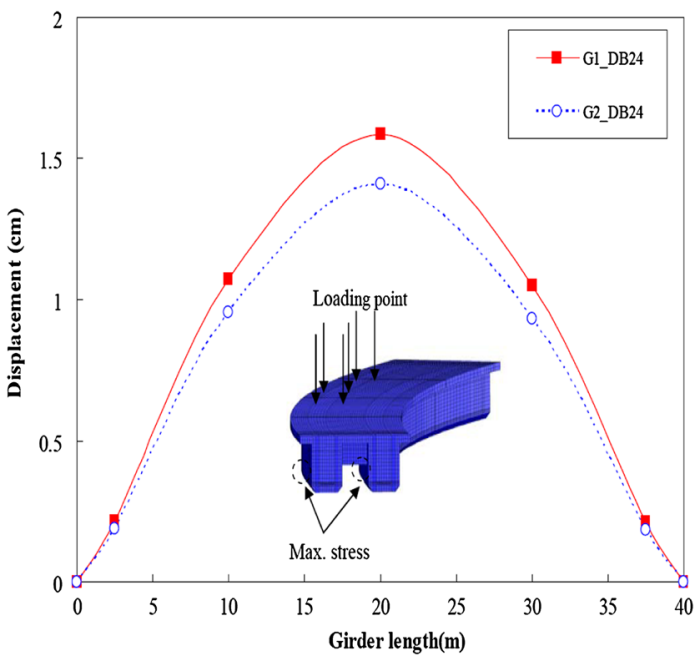

Fig. 5 Displacement results from the FE simulation of a curved bridge under KL-510 loading.

set the side walls to the target curvature of the girder. Also, the pressure applied to the side walls from cast concrete is resisted by jacks and fixture frames installed on exterior of the side walls. The frames have rollers on the top horizontal beams to slide the side walls to the desired positions. The side walls of the mold each consist of six steel plates that are $7500 \mathrm{~mm}$ in length, $2000 \mathrm{~mm}$ in height, and $12 \mathrm{~mm}$ thick. The side jacks are installed at an interval of $2500 \mathrm{~mm}$ for precise control of the side walls for the target curvature. The top horizontal beams assist the side fixtures in resisting the cast concrete pressure while also preventing the EPS block from floating up during the concrete casting. The jacks installed on the end mold caps are used to control the length and end angle of the girder and to resist the lateral pressure from the cast concrete. The three jacks are installed at both ends in a Z-configuration. The end molds are not fully affixed onto the side molds for simple adjustments when needed and to ensure a cost reduction by making them reusable. Smart Mold can be used to cast a curved PSC girder up to $50 \mathrm{~m}$ in length with a radius of curvature as high as $500 \mathrm{~m}$. After the casting of the girder and the removal of the formwork, the girder is lifted and moved using a lifting device specially designed to prevent the over-turning from occurring due to the curved configuration. The special lifting device is designed based on the concept of the centers of gravity of the cross-section and the curved girder to be aligned so that over-turning rotation is prevented, as shown in Fig. 2.

\section{Nonlinear 3D Simulation to Evaluate the Structural Performance}

In this study, a 3D nonlinear simulation using the commercial finite-element program DIANA was performed to predict the structural behavior for various design parameters of a precast PSC curved girder. Eight-node and six-node solid elements were used for the concrete, while bar and truss elements were used for the rebar and prestressing tendon, respectively. For the material model, the DruckerPrager and von Mises yield models were used for the concrete and for the PS tendon/steel reinforcement, respectively. The prestressing loss of the tendons was also considered. Modeling details of the PSC curved girder bridge are shown in Fig. 3.

In the model, the curved bridge consists of PSC hollow box girders, solid diaphragm sections, reinforced concrete (RC) cross beams, and an RC deck plate. For the boundary condition, hinge-roller supports were used, as shown in Fig. 3(a). The tendons and concrete were assumed to be perfectly bonded. Prestressing force was applied to the tendon as axial force in each truss member. Distributed selfweight and concentrated loads were applied to the bridge model until failure. 
Table 2 Load and displacement results from the FE Simulation.

\begin{tabular}{|c|c|c|c|c|}
\hline Type & Items & G1 & G2 & G3 \\
\hline \multirow[t]{4}{*}{ Two girder } & Yielding load (kN) & \multicolumn{2}{|c|}{2500} & \multirow[t]{4}{*}{-} \\
\hline & $\begin{array}{l}\text { Yielding displacement } \\
(\mathrm{mm})\end{array}$ & 89.1 & 86.9 & \\
\hline & Max. load (kN) & \multicolumn{2}{|c|}{2800} & \\
\hline & Max. displacement (mm) & 238.5 & 241.4 & \\
\hline \multirow[t]{4}{*}{ Three girder } & Yielding load (kN) & \multicolumn{3}{|c|}{5400} \\
\hline & $\begin{array}{l}\text { Yielding displacement } \\
(\mathrm{mm})\end{array}$ & 145.7 & 116.9 & 111.2 \\
\hline & Max. load $(\mathrm{kN})$ & \multicolumn{3}{|c|}{6400} \\
\hline & Max. displacement (mm) & 157.8 & 110.6 & 48.8 \\
\hline
\end{tabular}

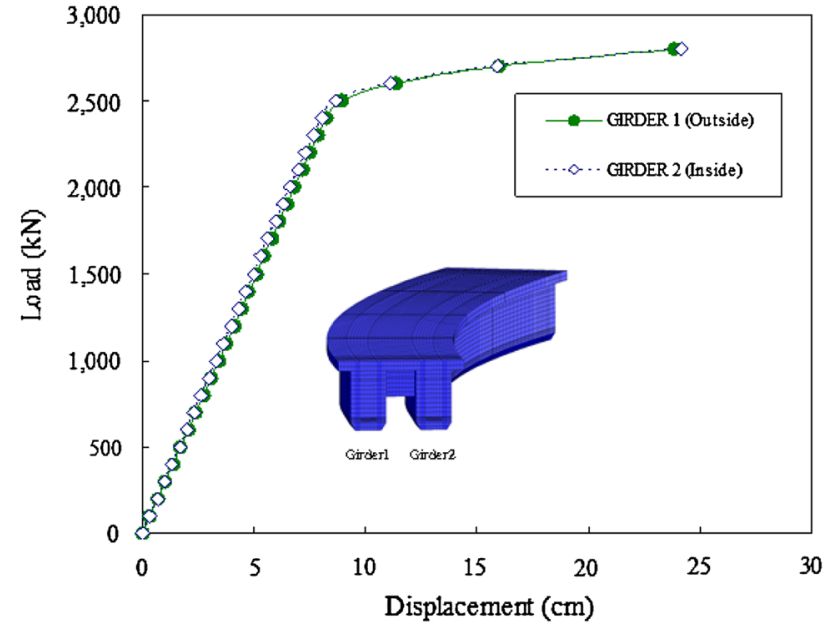

Fig. 6 Load-displacement curves from the FE simulation of the two-girder system.

\subsection{Simulation Parameters}

The parameters for the simulation were the number of girders, the loading location, the girder cross-section size, and the prestressing force. The outer girder and the inner girder with respect to the center of curvature have a larger and a smaller radius of curvature, respectively, with less and greater prestressing force, respectively. Static loading of 100 , 110,120 , and $130 \%$ of the actual prestressing force was applied to the curved bridge. Also, prestressing force combinations for the inner and outer tendons of 100 and $110 \%$ and 100 and $120 \%$ were used in the simulation. The parameters considered in the simulation are tabulated in Table 1.

\subsection{Vehicle-Loaded Bridge Simulation}

For a preliminary simulation of the precast PSC curved girder bridge, a vehicle load was applied to the bridge. A curved bridge model with a $40 \mathrm{~m}$-long span with two main PSC hollow box girders was used in the simulation. It was assumed that the bridge is a first-class bridge with a design load of KL-510. The Korean KL-510 truck load is a eightpoint load with various magnitudes. The KL-510 wheel load locations and magnitudes are shown in Fig. 4. The

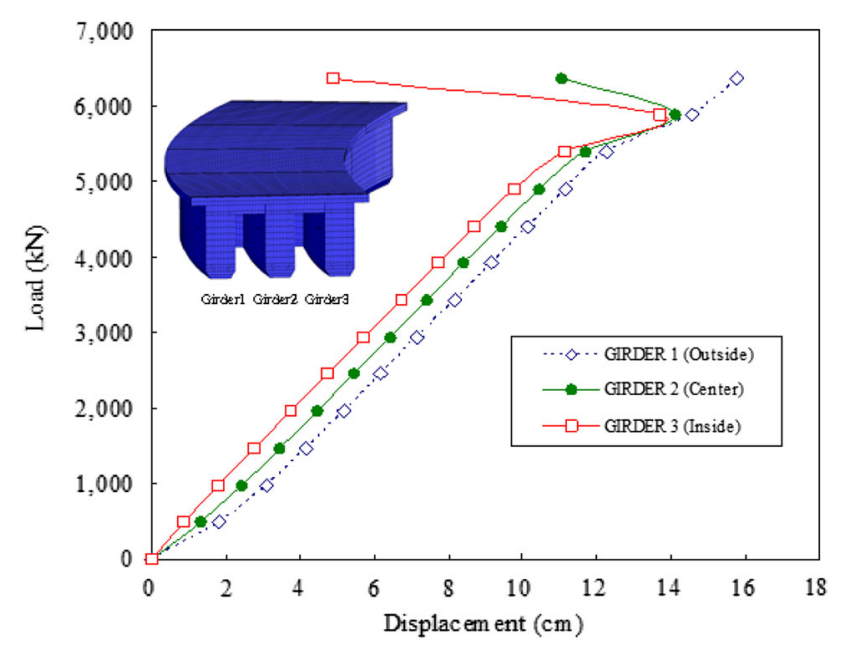

Fig. 7 Load-displacement curves from the FE simulation of the three-girder system.

simulation deflection result with respect to the span location of a two-girder curved bridge is shown in Fig. 5. The simulation result showed that the maximum deflections of the outer $(\mathrm{G} 1)$ and inner $(\mathrm{G} 2)$ girders were 1.6 and $1.4 \mathrm{~cm}$, respectively, at the center span, which is equivalent to approximately $30 \%$ of the code-allowed deflection of $5 \mathrm{~cm}$. The maximum compressive bending stresses of G1 and G2 were 9.7 and $10.1 \mathrm{MPa}$, respectively, at the center span. Because the allowable compressive bending stress is $42 \mathrm{MPa}$, the maximum compressive stresses of the girders are far less than the allowable stress, indicating the excellent load resisting capacity of the curved bridge.

\subsection{Comparison of Two- and Three-Girder Bridge System}

To understand the effect of the number of girders in a PSC curved bridge, simulations of the PSC curved girder bridge with two and three main girders were conducted. The results are shown and compared in Table 2 and Figs. 6 and 7. For the two-girder bridge, the yield and failure loads were approximately 2500 and $2800 \mathrm{kN}$, respectively, where the maximum deflection difference between G1 and G2 was $3 \mathrm{~mm}$. This deflection is significant, but stable coherent 
failure behavior between G1 and G2 was observed. For the three-girder bridge, the yield and failure loads were approximately 5400 and $6400 \mathrm{kN}$, respectively, indicating superior structural performance over the two-girder system. The increase in the load-carrying capacity of the three-girder

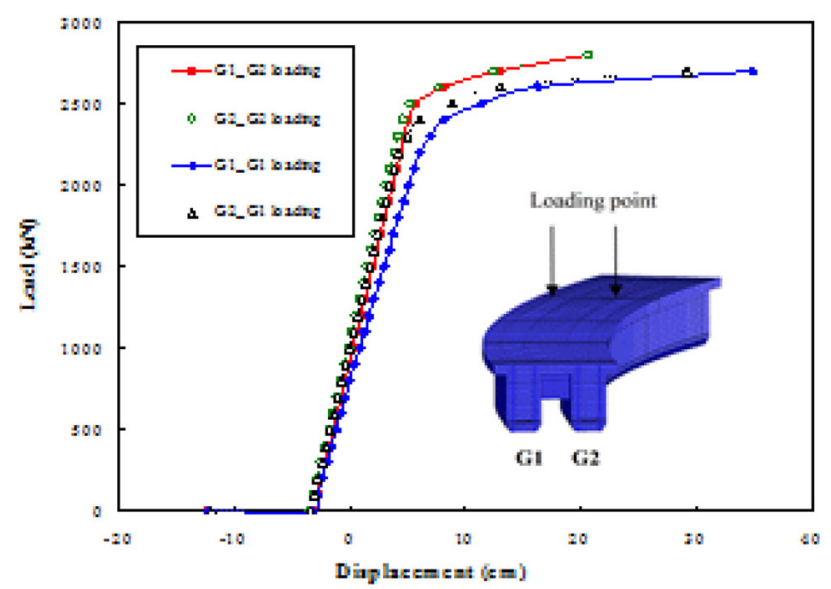

Fig. 8 Load-displacement curves from the FE simulation of various load points.

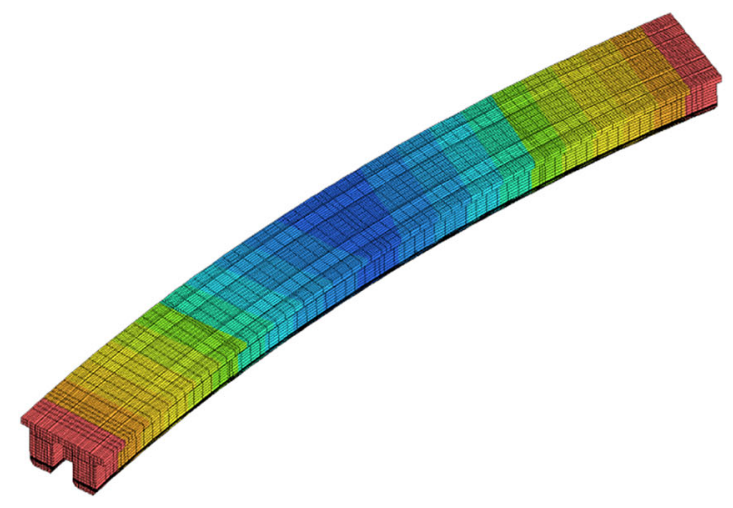

(a)

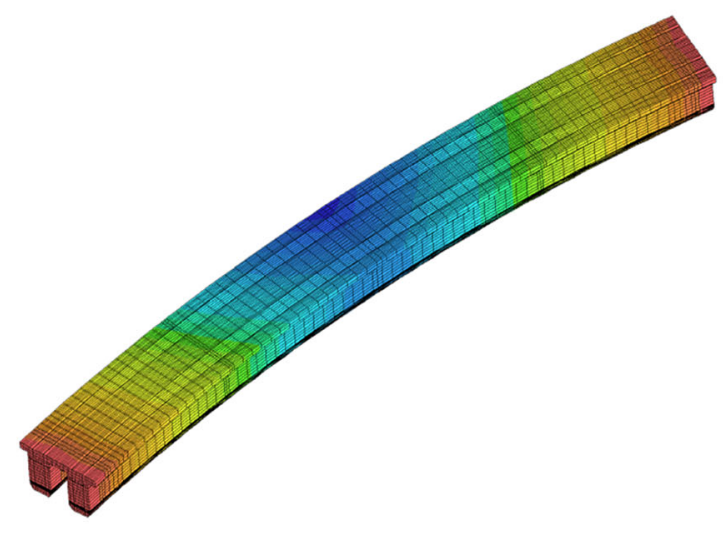

(b)

Fig. 9 Displacement patterns upon failure at loading: a G2 loading, b G1 loading. system can be attributed to the presence of an additional girder and a better distribution of stresses due to the increased rigidity along the centerline of the curved bridge. However, the difference in the maximum deflection between the inner (G3) and outer (G1) girders was $109 \mathrm{~mm}$, showing that the increased rigidity of the bridge from the addition of the middle girder increased both the load-carrying capacity and the deflection-induced rotation of the bridge.

\subsection{Load Point Variation}

As stated earlier, the inner (G2) and outer (G1) girders of a curved bridge have different lengths due to the difference in the radius of curvature, which would lead to different deflection behavior and load-carrying capacities depending on the loading location. To study the load point variation, a vertical concentrated load was applied on top of the inner and outer girder at the center span. These results are shown in Fig. 8. In the simulation results, the load-carrying capacity of the curved bridge appeared to increase when the load was applied onto G2 than on G1. Moreover, when the load was applied onto G1, the deflection difference between the inner and outer girders was greater than when the load was applied on G2. Between the elastic to yield states at loads of 1000 to $2300 \mathrm{kN}$, respectively, the deflection

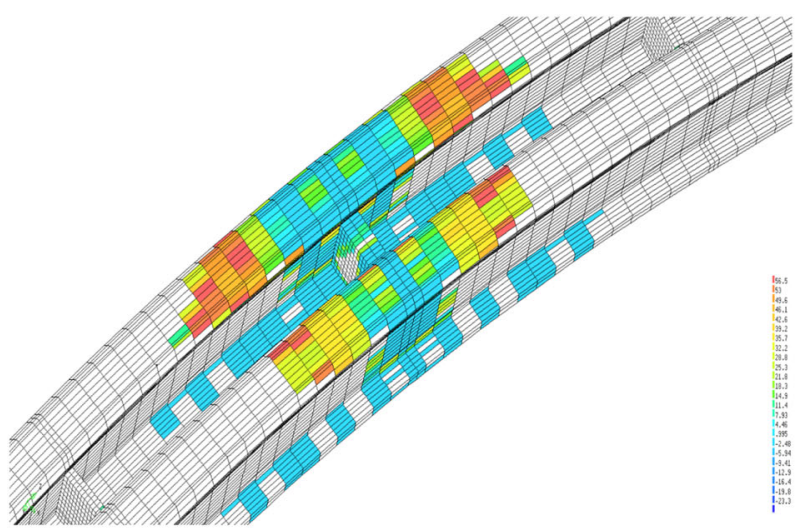

(a)

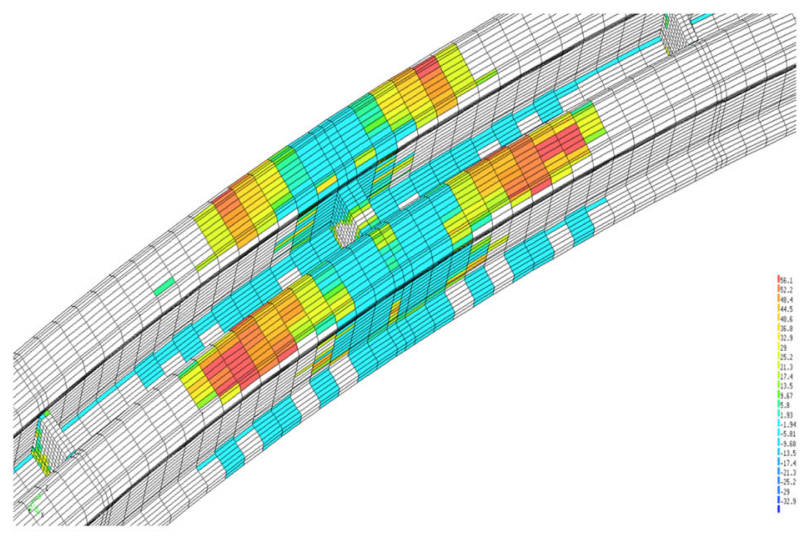

(b)

Fig. 10 Cracking pattern upon failure at loading: a G2 loading, b G1 loading. 
difference between the inner and outer girders became more distinct, equaling approximately $2 \mathrm{~cm}$, which would possibly cause critical safety problems in the bridge under a service loading condition.

The deflection and crack patterns of a failure load applied at various locations are shown in Figs. 9 and 10, respectively. The deflection pattern differed depending on the location of the applied load. When the load was applied on $\mathrm{G} 2$ or G1, the deflection pattern showed a fan-shaped or a concentric pattern, respectively. However, when the load point was switched to $\mathrm{G} 2$, the concentric pattern changed to a fan-shaped pattern.

The initial cracks appeared around the top surface of the loaded area. Then, as the load increased, additional cracks formed and propagated to the girders. The crack pattern at the point of failure showed that the cracks were concentrated at G2 when the load was applied on G1. However, when the load was applied on G2, similar concentrated cracks arose on both G1 and G2. These crack patterns can be attributed to the stress-transferring ability of the cross beams connecting the inner and outer girders, where a transfer from the outer to the inner girder is fully achieved while a transfer in opposite direction is only partially achieved. Similar to the deflection results of the two girders displacing in a coherent and an incoherent manner under the G1 and G2 applied loads, respectively, the crack pattern showed unsymmetrical and symmetrical patterns, respectively.

\subsection{Cross-Section Height Variation}

The cross-section height variations of the girders were simulated to understand the overall behavioral change of the curved bridge due to a dimensional change of the girders. The simulation results obtained after increasing the girder height by 5 and $10 \mathrm{~cm}$ are shown in Fig. 11. The yield and failure loads due to the height increases of 5 and $10 \mathrm{~cm}$ were 2600 and 2900 and 2700 and $3100 \mathrm{kN}$, respectively, relative to those of the original heights of 2500 and $2800 \mathrm{kN}$,

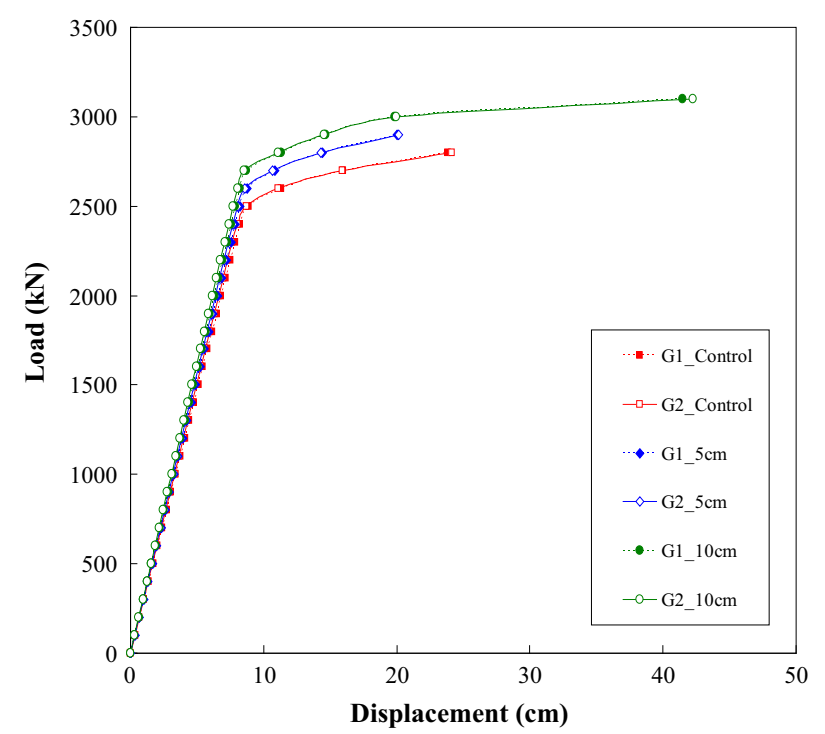

Fig. 11 Comparisons of load-displacement curves for a cross-sectional change. respectively. Clearly, the increased load-carrying capacities were due to the increase in the stiffness and cross-section area of the girders. However, the performance improvement of the bridge after increasing the girder dimensions can be restricted by the requirements of the total girder depth and the effective prestressing force, cost, constructability, and other factors.

\subsection{Prestressing Force Variation}

The prestressing force variations of the girders were simulated to understand the overall behavioral change of the curved bridge upon increasing the PS force. The simulation results after increasing the PS force to $130 \%$ of the design PS force are shown in Fig. 12. As shown in the figure, the

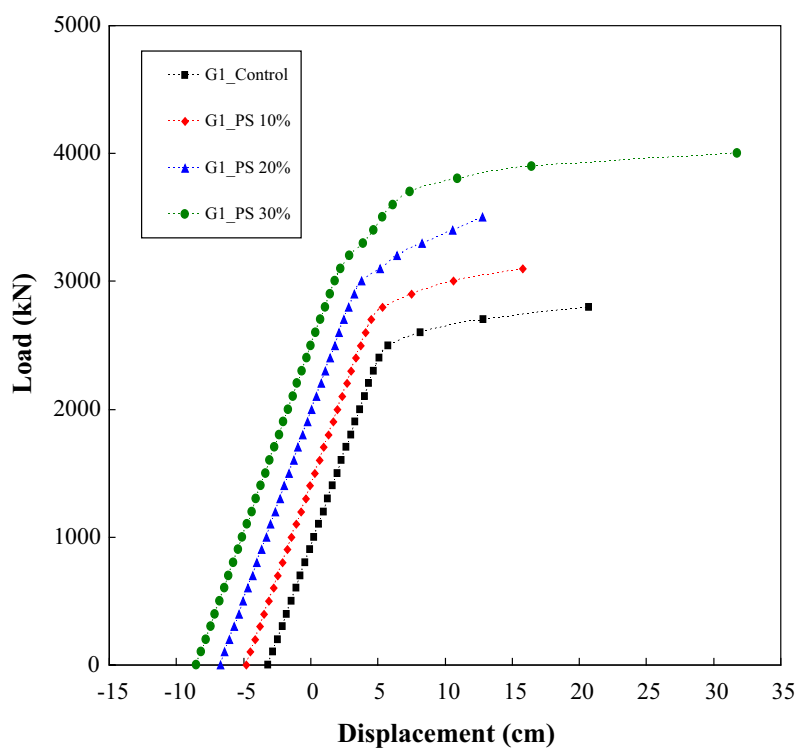

(a)

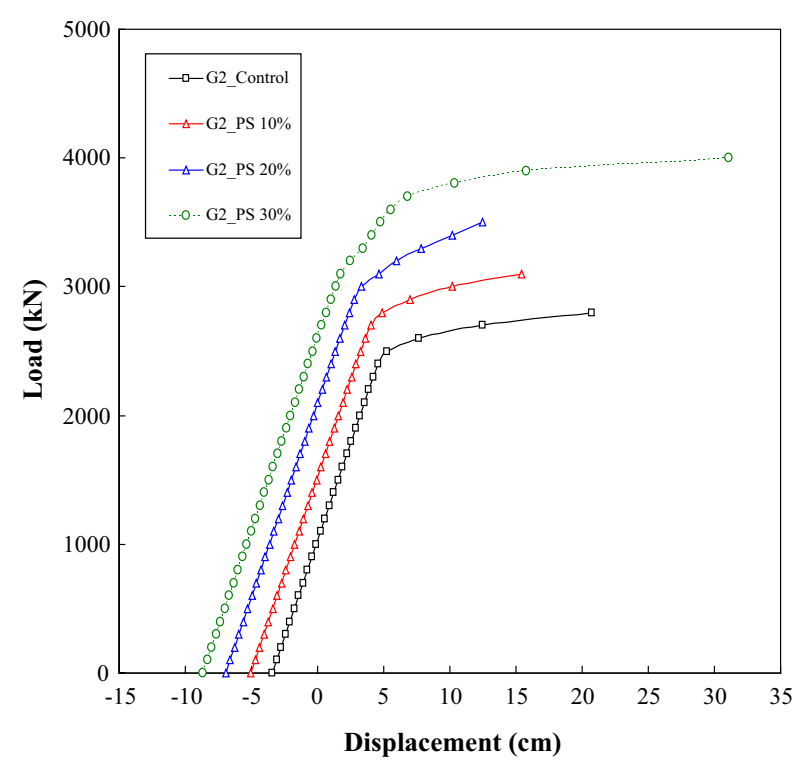

(b)

Fig. 12 Comparisons of load-displacement curves for a change in the prestressing force: a G1 girder, b G2 girder. 
initial cambering and failure load of the girder increased in proportion to the increase in the PS force for both G1 and G2. The deflection difference between G2 and G1 tended to decrease as the PS force increased. The simulation results showed that an increase in the PS force is the most effective way to improve the structural performance of precast PSC curved girder bridges. However, in order to increase the PS force, various parameters, including the number of strands, the strand strength, and the concrete strength of the bridge must be considered in the design.

The reaction forces obtained from the simulation of variations in the PS force are shown Fig. 13. The figure shows that the reaction force on G1 was three times of that on G2, which was caused by the overturning moment created from the curvature difference between $\mathrm{G} 1$ and G2. The reaction force difference became larger as the curvature radius became smaller. Also, as the PS force increased, the reaction force on G2 decreased. More precisely, when the PS force was increased to $130 \%$, the reaction was reduced by $60 \%$ compared to that of the control condition $(100 \%$ of the design PS force). If the PS force is increased to $150 \%$, negative reaction forces are expected to occur, which may lead to a fatal overturning failure of the bridge.

\subsection{Outer Girder Prestressing Variation}

The PS force variation of the outer girder (G1) was simulated to understand the overall behavioral change of the bridge with an increase in the PS force in G1. The simulation results after increasing the PS force in G1 by 10 and $20 \%$ from the design PS force are shown in Fig. 14. The figure shows that the load-carrying capacities of both girders increased as the PS force in the outer girder increased. The maximum loads determined after a $10 \%$ increase in the PS force in both G1 and G2 and a $20 \%$ increase in the PS force in only G1 were 3100 and $3200 \mathrm{kN}$, respectively, indicating superior performance upon an increase in the PS force in only G1. The application of greater PS force in the outer

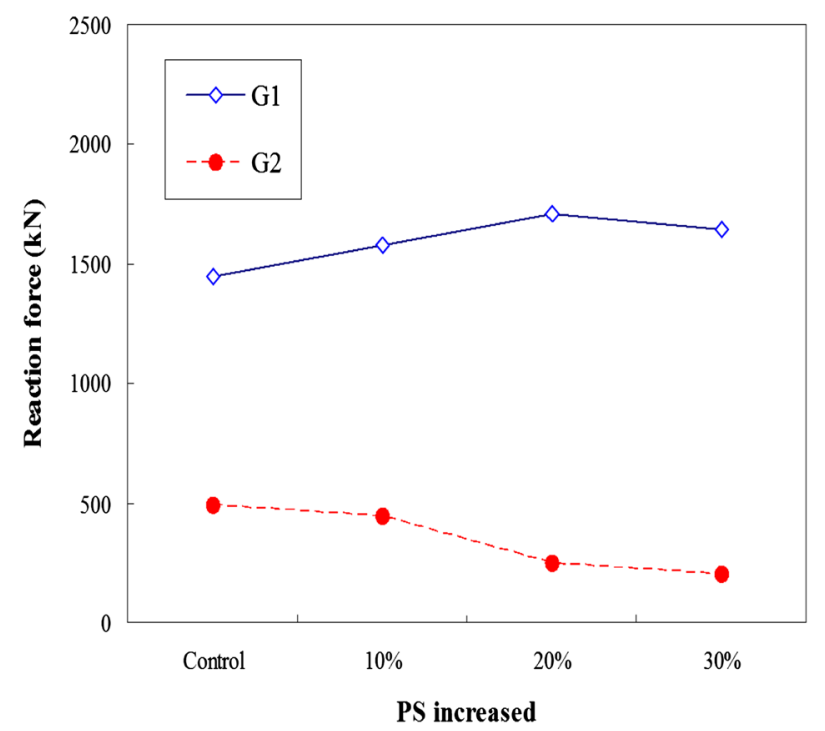

Fig. 13 Change of the reaction force due to prestressing force variations.

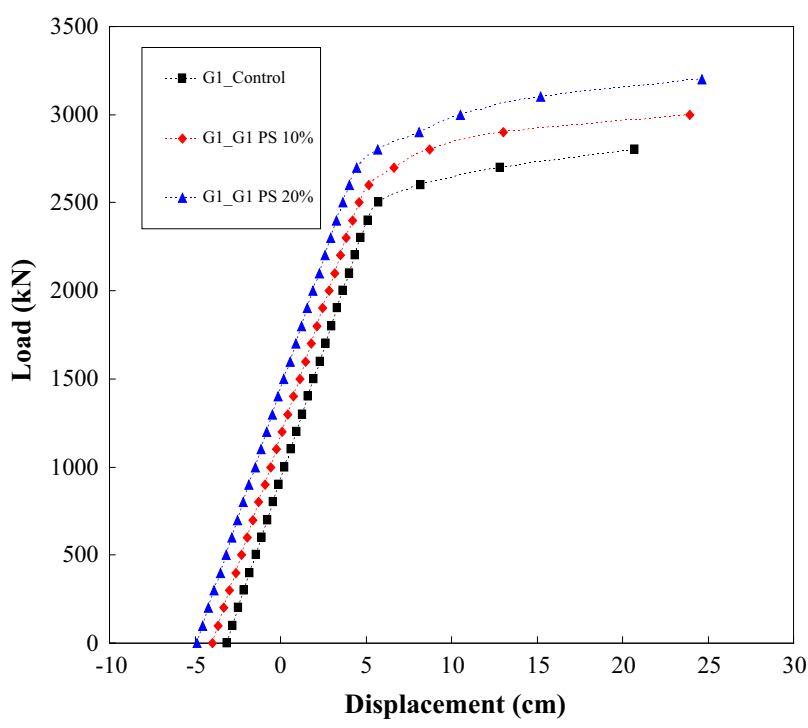

(a)

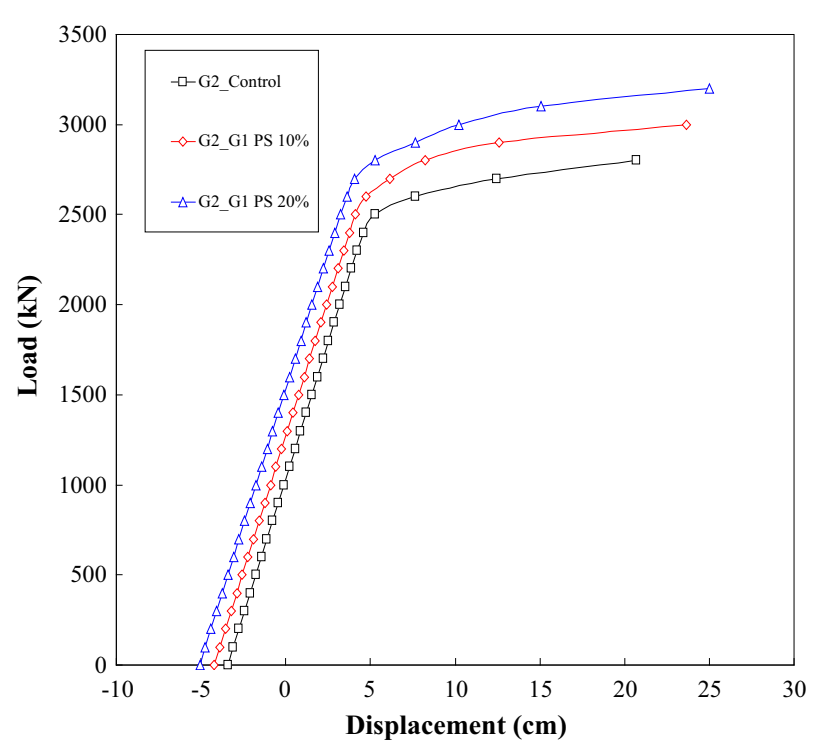

(b)

Fig. 14 Load-displacement curves from different prestressing forces in the girders: a G1 girder, b G2 girder.

girder than in the inner girder improved the stability of the curved bridge and appeared to compensate for the differences in the curvature and span length between the two girders.

\section{Full-Scale Static Experiment}

A full-scale structural test was performed to evaluate the structural performance of a precast PSC curved two-girder bridge constructed using the Multi-tasking formwork. A two-girder curved bridge with a $40 \mathrm{~m}$ span was selected to represent the small and medium-span bridge of the type that can be built in metropolitan areas. The structural performance test was a static three-point loading test for evaluating the structural and failure behavior of the bridge. 


\subsection{Test Specimen Details}

The bridge specimen was a precast PSC curved two-girder bridge with a span length, deck width, and average curvature radius of 40, 5, and $100 \mathrm{~m}$, respectively. The dimensions of the test specimen were selected considering space availability and the test setup feasibility of the large-scale testing lab. The geometry and dimensions of the bridge specimen are shown in Fig. 15. The design compressive strength of the concrete used for the girders, cross beams, and deck were 45, 27, and $27 \mathrm{MPa}$, respectively. SD $40 \mathrm{HD} 13$ and HD25 were used for the shear and longitudinal reinforcements, respectively, while SWPC 7BL with $15.2 \mathrm{~mm}$ low-relaxation steel strands was used for the PS strands. The material properties of the concrete, reinforcements, and PS strands are tabulated in Table 3.

The fabrication sequence of the specimen was in accordance with the work sequence used in the field when the Multitasking formwork is used as the formwork for the construction of precast PSC hollow girders. An EPS foam block was inserted to create a hollow cross-section of the specimen so as to enhance its torsional resistance and reduce its self-weight. The bridge specimen was a two-main-girder type with an outer (G1) and an inner girder (G2). After the two girders were constructed and positioned, RC cross beams and the deck were cast in situ at the work yard in front of the testing lab. Photos from the fabrication process are shown in Fig. 16 in the following sequence: (1) Smart Mold setup, (2) rebar assemblage and sheath tube installation, (3) Smart Mold side wall adjustments for the target curvature, (4) girder concrete casting, (5) steam curing and Smart Mold removal, (6) prestressing application, (7) girder lifting for positioning, (8) RC cross beam casting, (9) RC deck casting, and (10) the finished bridge.

To adjust the curvature of the side walls, precise positioning was achieved using surveying tools. The rebar network was fabricated as a single piece with the design
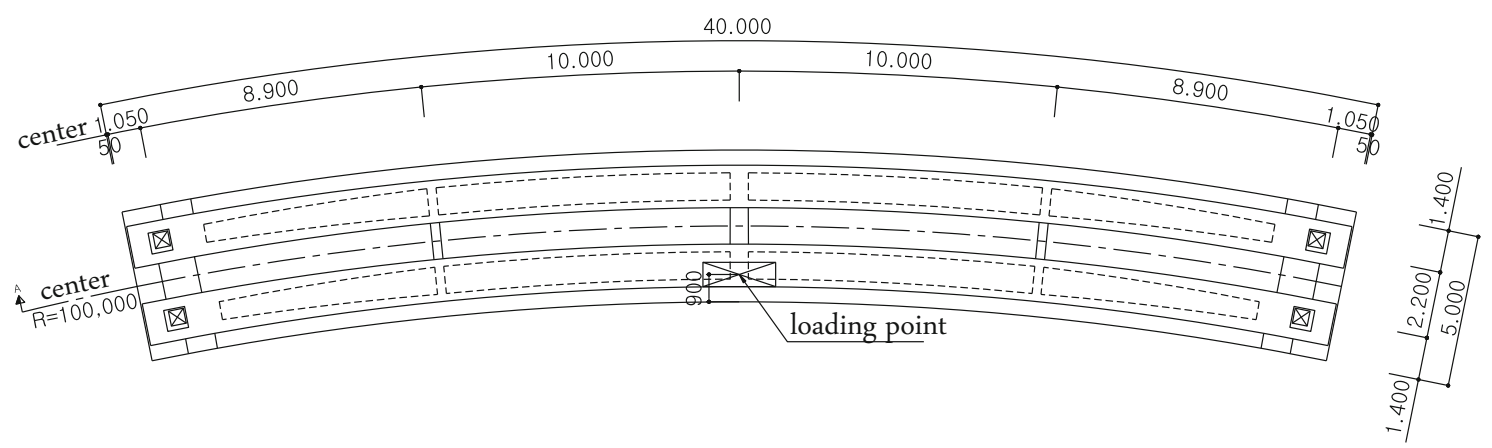

(a)

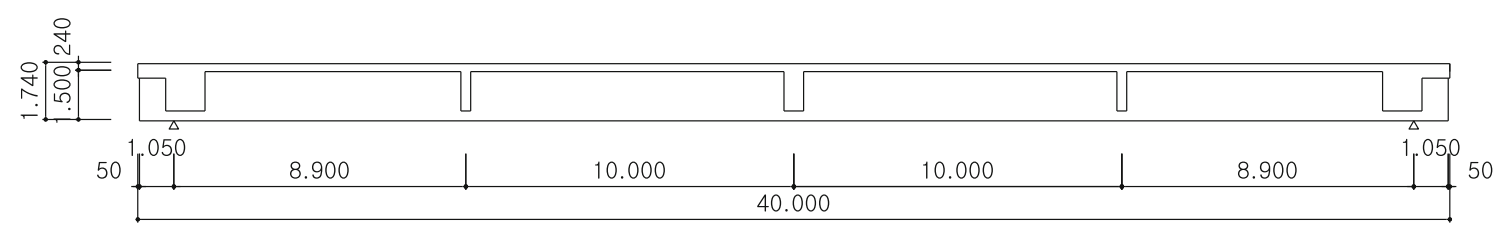

(b)

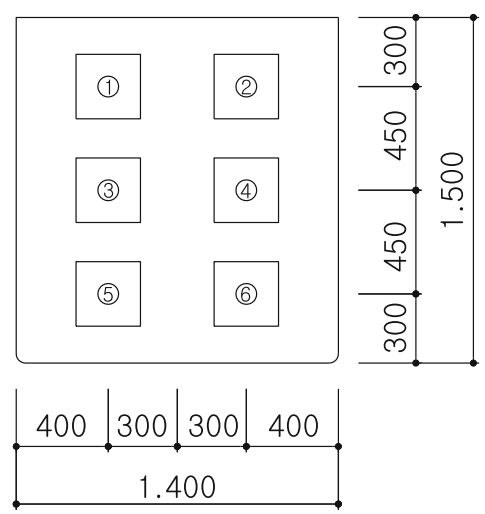

(c)

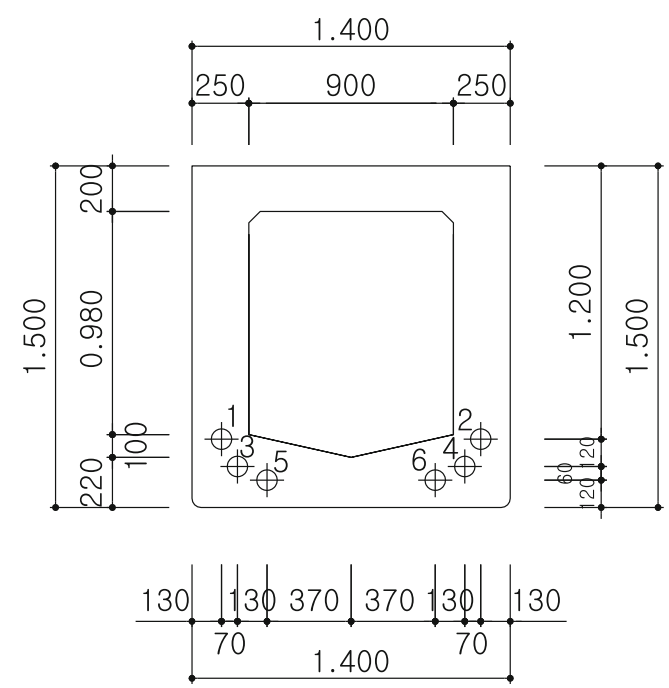

(d)

Fig. 15 Concrete PSC curved bridge geometries and dimensions: a Plan view, b longitudinal view, $\mathbf{c}$ end section, $\mathbf{d}$ center section. 
Table 3 Material properties used in the FE simulation.

\begin{tabular}{|c|c|c|c|c|}
\hline Materials & Members & \multicolumn{2}{|c|}{ Items } & Design values (MPa) \\
\hline \multirow[t]{4}{*}{ Concrete } & \multirow[t]{3}{*}{ Girder } & \multicolumn{2}{|c|}{ Design strength } & 45 \\
\hline & & \multirow[t]{2}{*}{ Allowable stresses } & Compression & 21.6 \\
\hline & & & Tension & -1.5 \\
\hline & Deck slab & \multicolumn{2}{|c|}{ Design strength } & 27 \\
\hline Rebars & & \multicolumn{2}{|c|}{ Yield strength } & 400 \\
\hline \multirow[t]{3}{*}{ PS strand } & & \multicolumn{2}{|c|}{ Ultimate strength } & 1900 \\
\hline & & \multicolumn{2}{|c|}{ Yield strength } & 1600 \\
\hline & & \multicolumn{2}{|c|}{ Allowable tensile stress } & 1280 \\
\hline
\end{tabular}

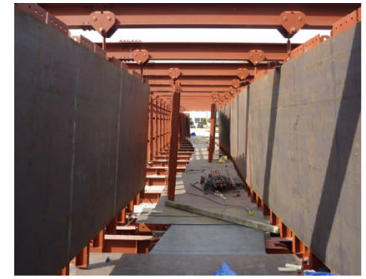

(a)

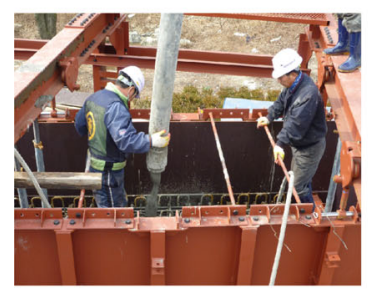

(d)

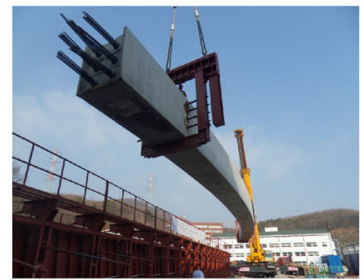

(g)

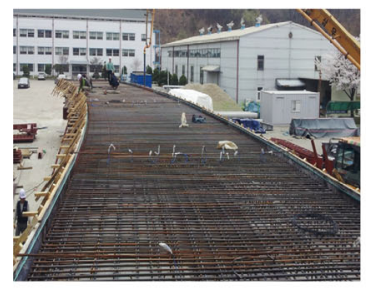

(j)

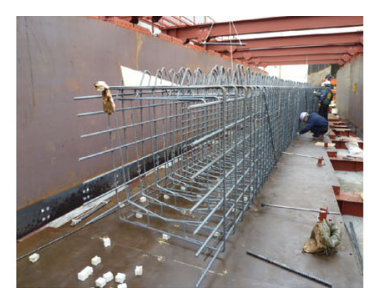

(b)

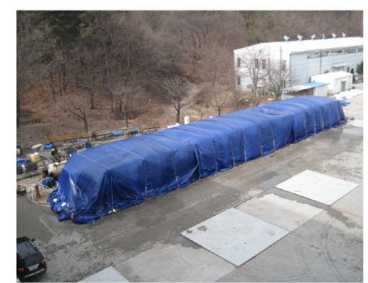

(e)

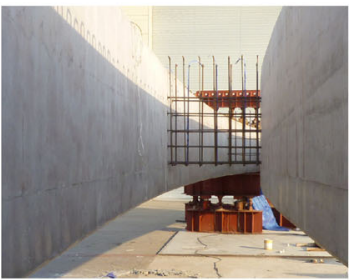

(h)

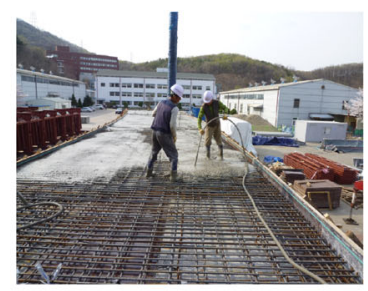

(k)

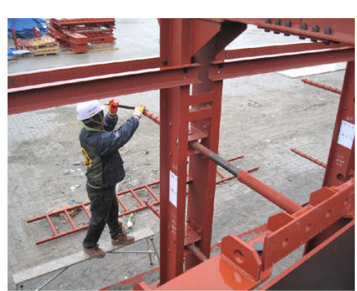

(c)

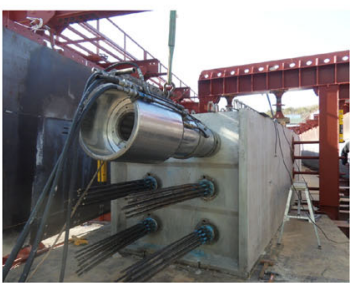

(f)

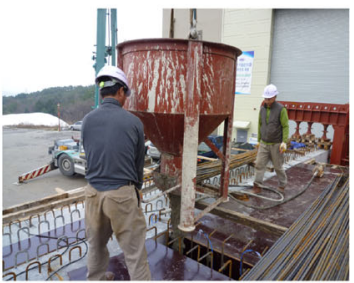

(i)

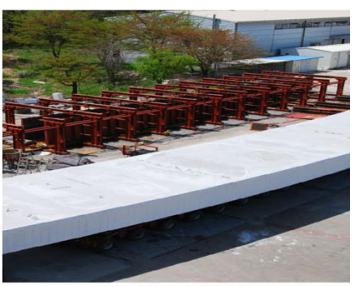

(l)

Fig. 16 Manufacturing process of the PSC curved bridge: a Formwork assemblage, b rebar assemblage, c side jack control, d concrete casting, e steam curing, $\mathbf{f}$ prestressing, $\mathbf{g}$ girder lifting, $\mathbf{h}$ cross beam rebar, $\mathbf{i}$ cross beam concrete casting, j deck rebar, $\mathbf{k}$ deck concrete casting, $\mathbf{l}$ finished bridge.

dimensions and configuration to be placed precisely in the Smart Mold. The cross beam and deck rebar arrangements are shown in Figs. 17 and 18, respectively. Shear studs are used to connect the deck plate with the cross beams and girders so as to integrate the system as a unified structure.
When the girders are not fixed to the cross beams and the deck plate, different cambering deflections can occur in the inner and outer girders due to the PS difference, leading to an overturning failure during the test. The difference between a straight and curved girder applied with PS force is 


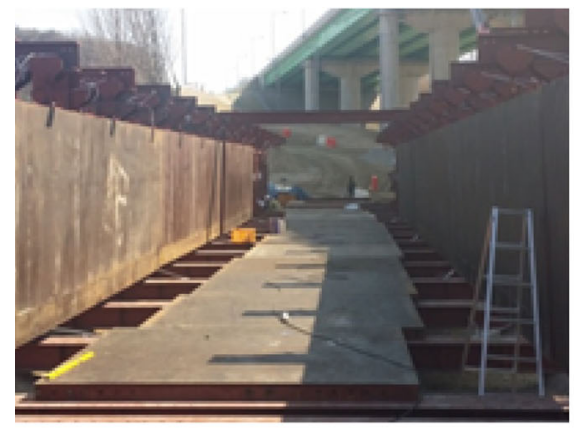

(a)

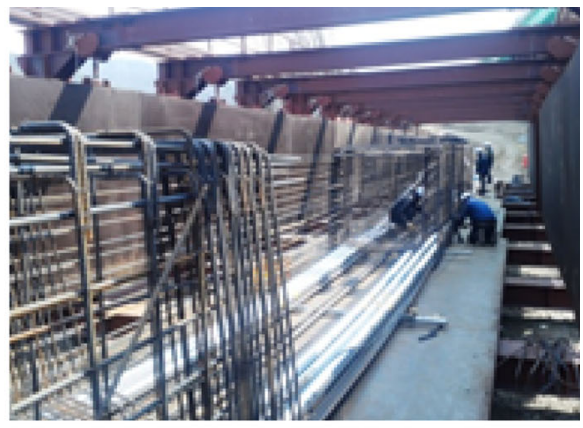

(b)

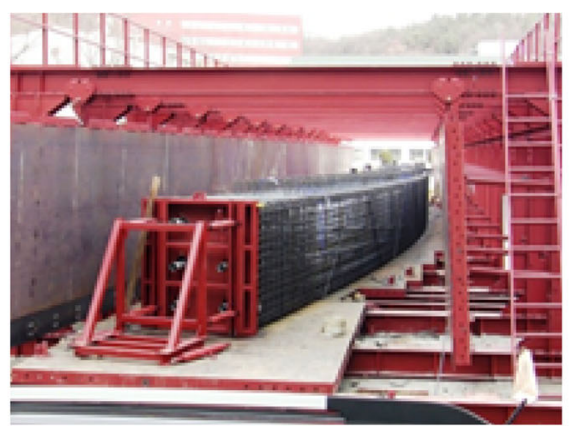

(c)

Fig. 17 Formwork and rebar constructions: a Formwork assemblage, b rebar assemblage, c finished rebar system.

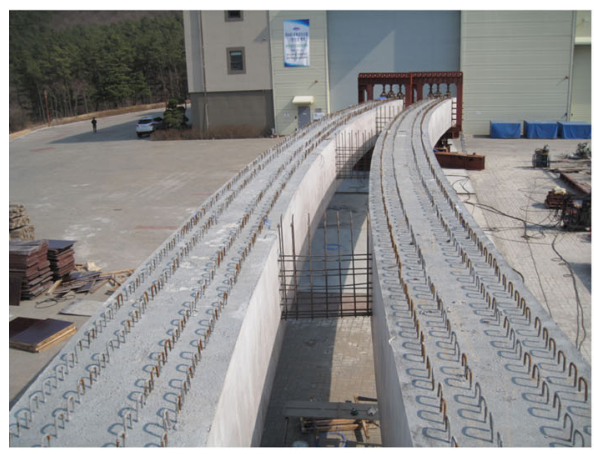

(a)

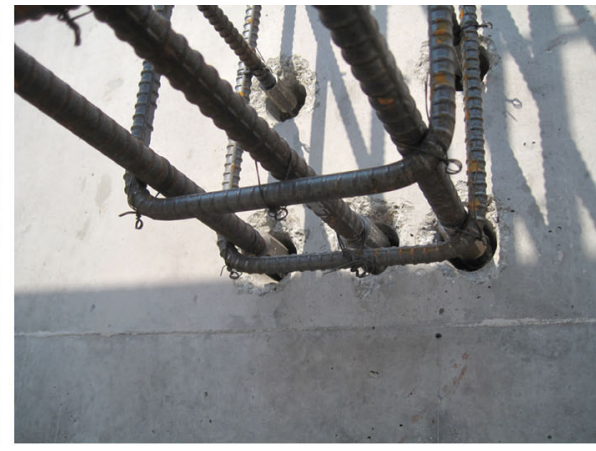

(b)

Fig. 18 Cross beam details: a Cross beams, b cross beam reinforcements.
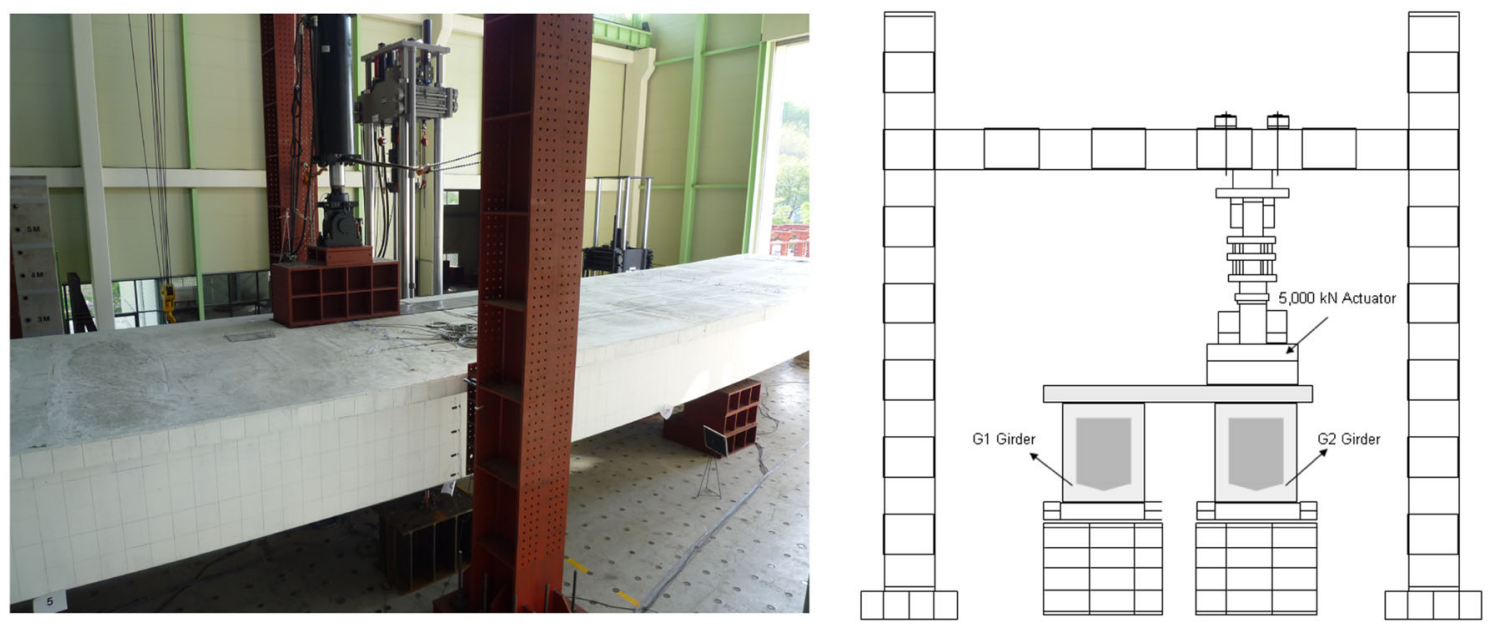

Fig. 19 Test setup. 

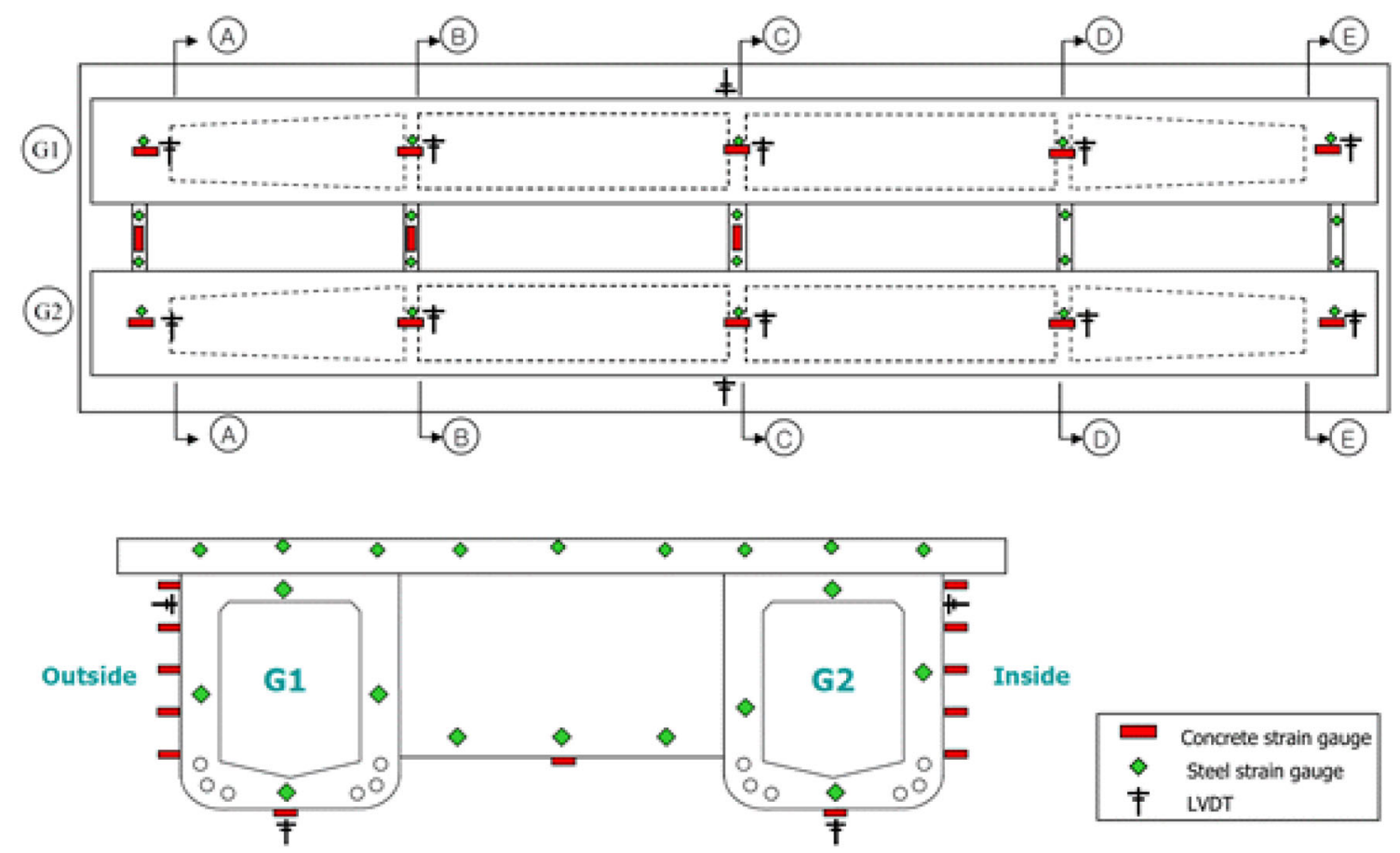

Fig. 20 Gauge locations.

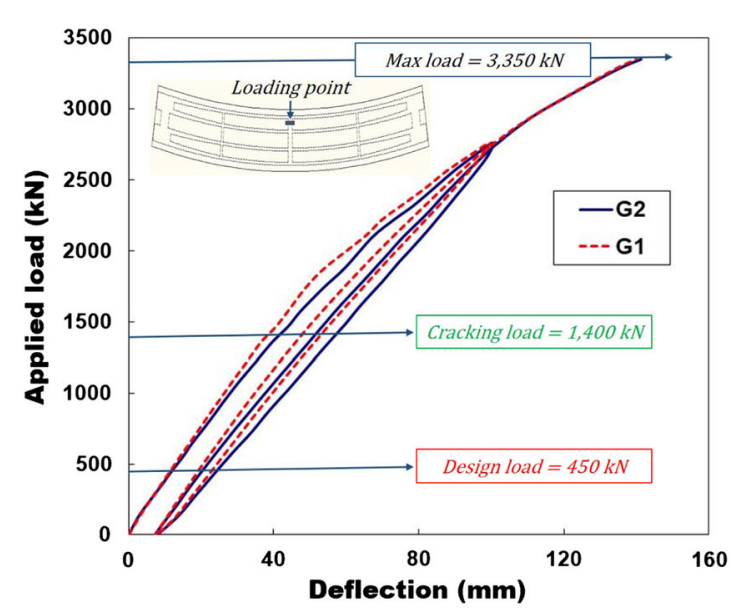

(a)

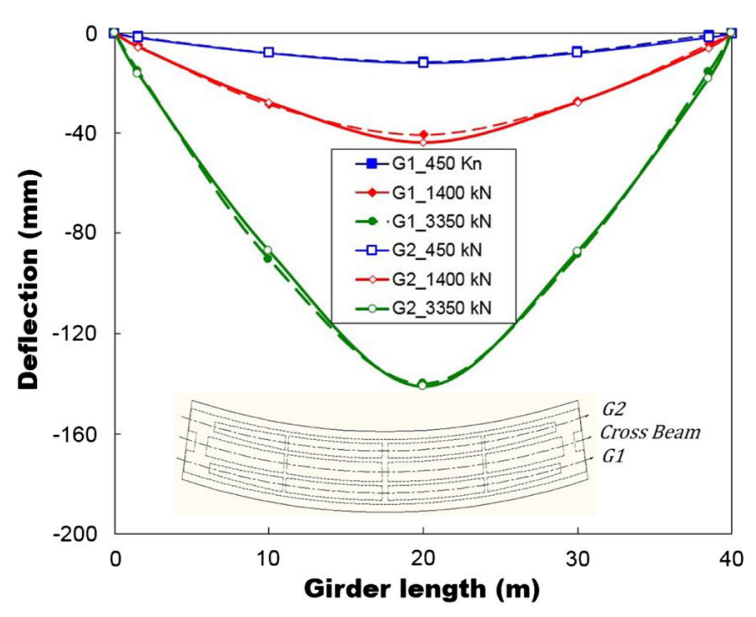

(b)

Fig. 21 Load-deflection relations: a Center span deflection, b deflection along the length.

Table 4 Displacement results at cross beam locations for various load stages.

\begin{tabular}{c|c|c|c|c|c|c|c}
\hline \multirow{2}{*}{ Load step } & \multirow{2}{*}{ Load (kN) } & \multicolumn{3}{|c|}{ Deflection (mm) } & \multicolumn{2}{|c}{$3 L / 4$} \\
\cline { 3 - 8 } & & \multicolumn{2}{|c|}{$L / 4$} & $\mathrm{G} 1$ & $\mathrm{G} 2$ & $\mathrm{G} 1$ & $\mathrm{G} 2$ \\
\cline { 3 - 9 } & & $\mathrm{G} 1$ & 7.8 & 11.3 & 11.7 & 7.3 & 7.74 \\
\hline \hline Design load & 450 & 7.7 & 27.64 & 40.5 & 43.8 & 27.2 & 27.58 \\
\hline Cracking load & 1400 & 28.4 & 87.18 & 139.9 & 141.2 & 88.5 & 87.26 \\
\hline Max. load & 3350 & 90.3 & & & & \\
\hline
\end{tabular}

that cambering induced in a straight girder is stable without overturning rotation while that induced in a curved girder is unstable with overturning rotation. A photo of transporting of the girder using an overturning prevention lifting device is shown in Fig. 16g. Once the girder is placed in the device, the center of gravity of the curved girder and the cross- section is aligned so that the global overturning of the girder is prevented.

\subsection{Test Setup and Data Measurement Details}

A structural performance evaluation test of the precast PSC curved two-girder bridge was conducted by applying 


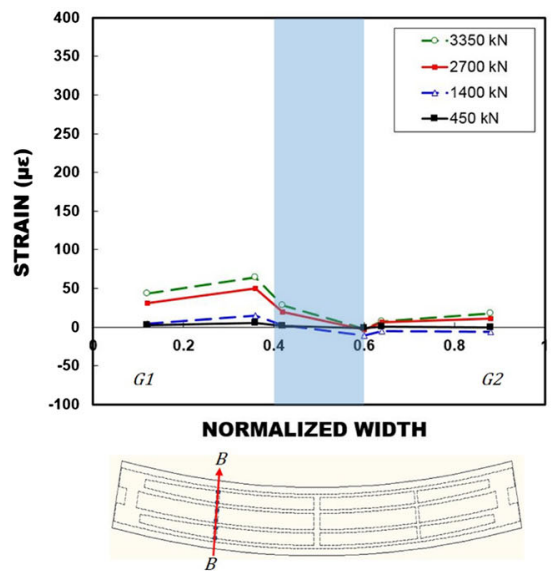

(a)

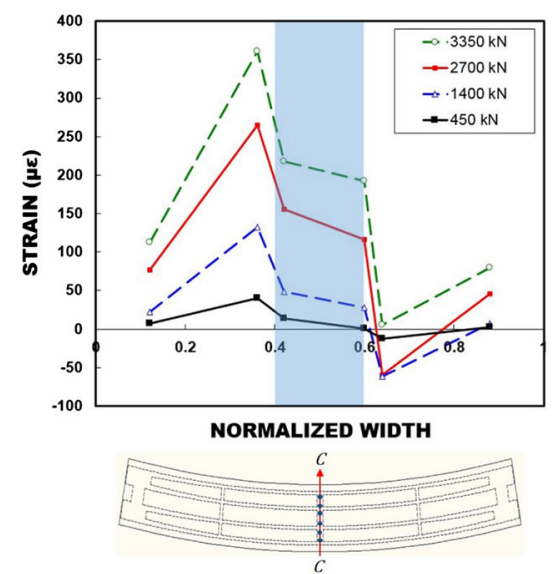

(b)

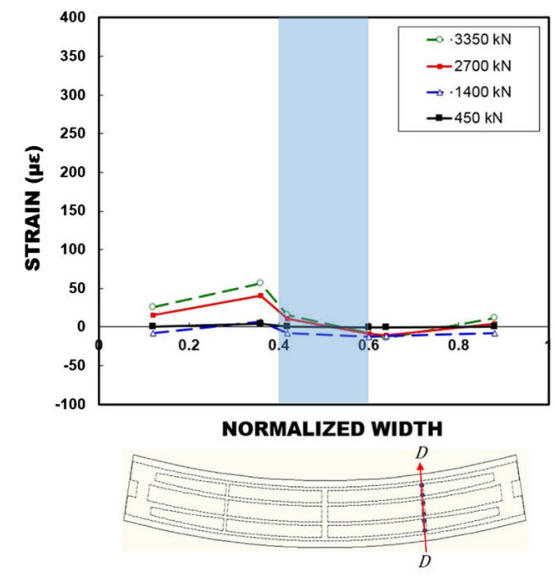

(c)

Fig. 22 Horizontal rebar strains at cross beam locations: a B-section, b C-section (center), c D-section.

three-point loading with a hinge-roller support condition. The test setup and the loading device are shown in Fig. 19. To prevent the possibility of an overturning failure of the specimen during the test, a steel frame was placed at both sides of the support. Because the center of gravity of the specimen is not located at the center, the load was applied on the deck above G2 near the plan centroid of the bridge to mitigate the risk of overturning. A static actuator with a maximum capacity of $5000 \mathrm{kN}$ was used for loading, with a load increment of $30 \mathrm{kN} / \mathrm{min}$. Although the specimen did not reach its ultimate state, the load was applied only up to $3400 \mathrm{kN}$ to ensure test safety.

The strain measurements for each load increment were obtained from strain gauges placed on the concrete and the reinforcement and from a linear variation deformation transducer (LVDT) placed at the bottom and on the sides of the girder. In order to measure the strain from various depths of the girder to obtain the neutral axis movement behavior, strain gauges were placed at the center span of the girder with a constant depth increment of $300 \mathrm{~mm}$. Rebar strain gauges were placed on the top and bottom rebars of the deck in the vertical and lateral directions. Three LVDTs were placed at the $L / 4,2 L / 4$, and $3 L / 4$ locations to measure the

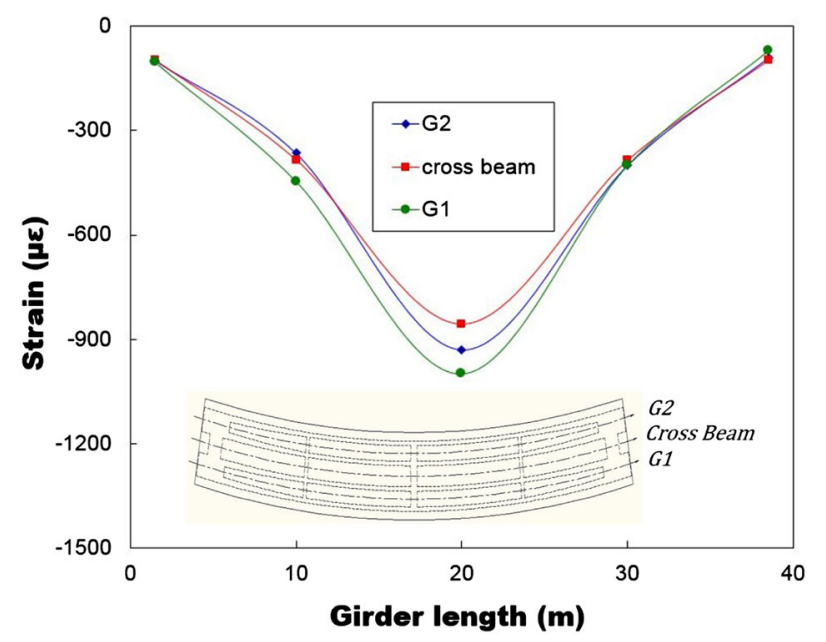

Fig. 23 Longitudinal rebar strains at the maximum load. vertical displacement at quarter-span intervals. Also, a LVDT was placed on the side surface of the center span to measure the horizontal displacement. The placement locations of the strain gauges and LVDTs are shown in detail in Fig. 20.

\section{Experimental Results and Discussions}

\subsection{Load-Displacement Relation}

The load-deflection relationships measured from the bottom of the two girders at the center span are shown in Fig. 21a. The deflection measurements of G1 and G2 from the vertical LVDTs at the supports, $L / 4,2 L / 4$, and $3 L / 4$ for various load increments, are shown in Fig. 21b. The specimen showed elastic behavior at the design load of $450 \mathrm{kN}$ with the two girders deflecting in a coherent manner. The initial cracking load was $1400 \mathrm{kN}$, with cracks forming at both the left and right end diaphragms, which were located $10 \mathrm{~m}$ away from the center span of the outer girder (G1). The cracking load was approximately three times the design load, verifying the safety and serviceability of the curved bridge. Until the load reached $1400 \mathrm{kN}$, the specimen behaved in a stable and elastic manner. However, when the initial cracks appeared, the slope of load-deflection relationship of the outer girder (G1) changed. In contrast, the inner girder $(\mathrm{G} 2)$ behaved in an elastic manner until the maximum load was reached.

The deflection measurements obtained from the LVDTs at the $L / 4,2 L / 4$, and $3 L / 4$ locations for the design, cracking, and maximum loads are tabulated in Table 4 . The results show that the deflection of G1 at the center span was less than that of G2 due to the load being applied onto G2. The deflection results shown in Fig. $21 \mathrm{~b}$ verify that the deflection difference between G1 and G2 was minor due to the effective stress transfer by the cross beams and the structural continuity between the girders, the cross beams, and the deck. The deflection data obtained from the experiment and the simulation are in good agreement. The deflections at the design load for G1 and G2 at the center span were 11.3 and 


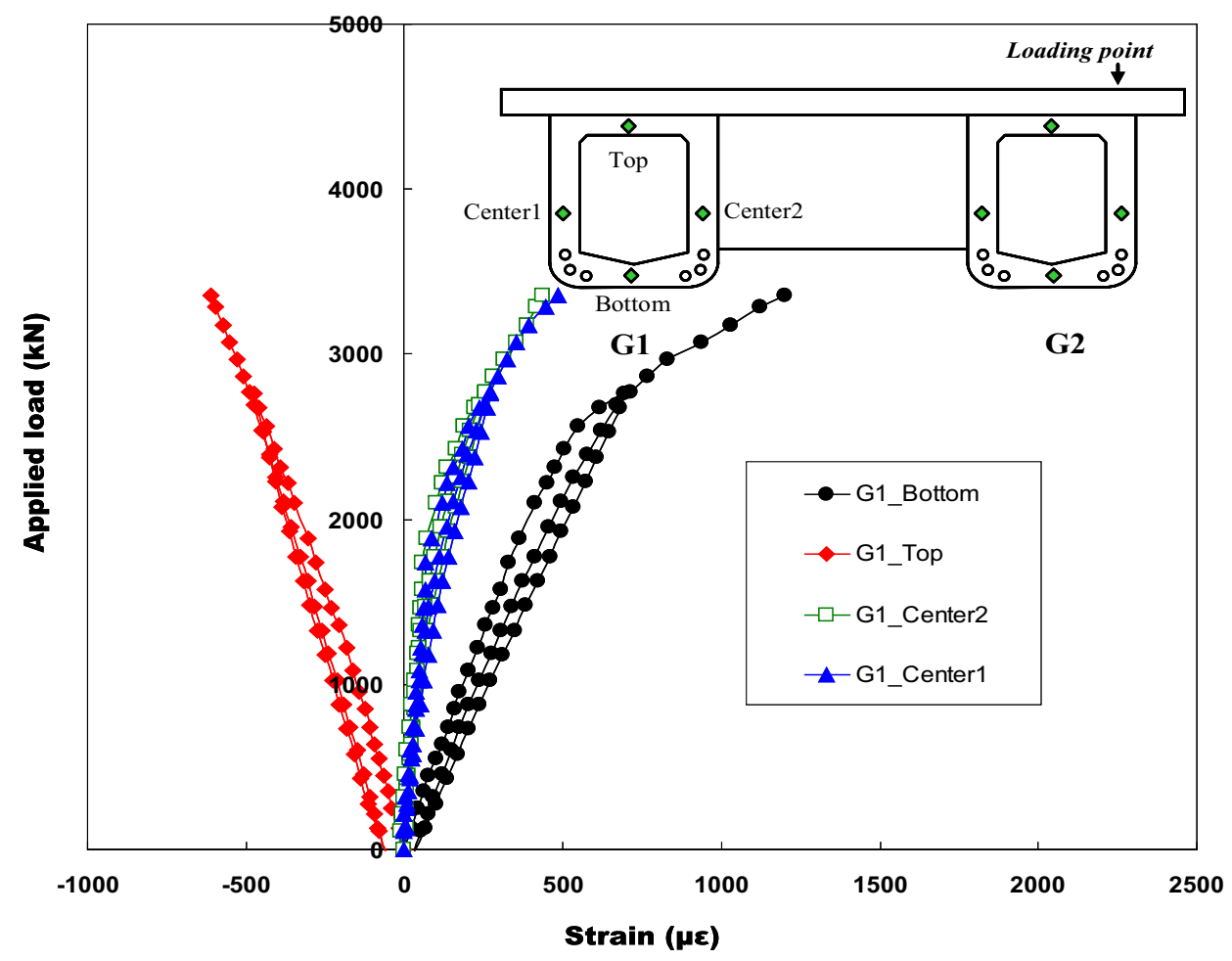

(a)

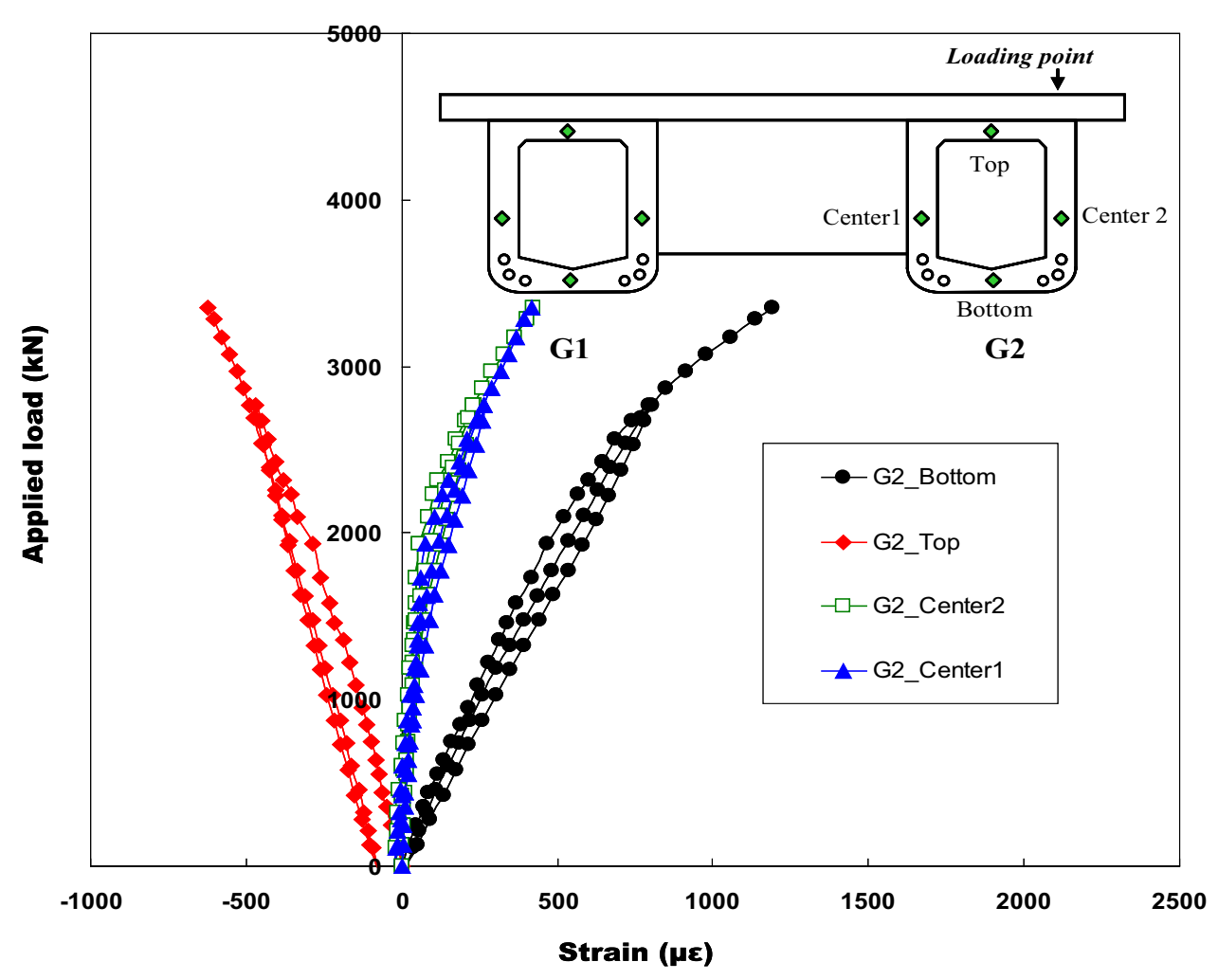

(b)

Fig. 24 Longitudinal rebar strains at the center: a G1 girder, b G2 girder.

$11.7 \mathrm{~mm}$, respectively, while those at the crack load were 40.5 and $43.8 \mathrm{~mm}$, respectively. The required deflection limit of $50 \mathrm{~mm}$ was not exceeded for both the design and crack deflections of the bridge, once again verifying its excellent serviceability performance. The applied load at which the required deflection of $50 \mathrm{~mm}$ occurred was $1800 \mathrm{kN}$, far exceeding the crack load and confirming the safety of the bridge. 


\subsection{Load-Strain Relation}

The load-strain relationships measured from the top horizontal rebars of the cross beams located at $L / 4,2 L / 4$, and $3 L / 4$ for various load increments are shown in Figs. 22a to 22c, respectively. As shown in Fig. 22b, the compressive strains at the area around the load point increased continuously as the load increased. Even at the cracking load of $1400 \mathrm{kN}$, the strains at the area around the load point remained compressive until becoming tensile at the load of $2700 \mathrm{kN}$. Unlike the compressive strain measured at the load point area, the tensile strains were measured from both the cross beams at the $L / 4$ and $3 \mathrm{~L} / 4$ positions, with greater tensile strain occurring in the outer girder $(\mathrm{G} 1)$ than in the inner girder $(\mathrm{G} 2)$. The larger strain levels in $\mathrm{G} 1$ than in $\mathrm{G} 2$ were due to the lower cross-sectional stiffness of the cross beam (i.e., normalized width between 0.4 and 0.6) compared to that of the girder, causing greater tensile strain at outer region than at the inner region of the curved bridge. Unlike the large strain measured from the cross beam at the center span, the cross beams at $L / 4$ and $3 L / 4$ showed smaller strains, indicating good stress distributions from $\mathrm{G} 1$ and G2 through the cross beams. Also, the strains measured from the two cross beams were symmetric, validating the good unity of the girders, the cross beams, and the deck. The maximum longitudinal strains measured from longitudinal rebars of the center of G1, the cross beam, and G2 at the supports, $L / 4,2 L / 4$, and $3 L / 4$ are plotted as shown in Fig. 23. As expected, the maximum strains occurred at the center span, with the G1 strains being larger than the $\mathrm{G} 2$ strains when $\mathrm{G} 2$ was loaded. Because the radius of curvature of G1 is greater than that of $\mathrm{G} 2$, the longer length of G1 induced greater strain in $\mathrm{G} 1$. The strain measured from the center of the cross beam at the center span $(L / 2)$ was less than the strains of G1 and G2. Because the cross beam was designed to transfer the stresses in the lateral direction, its longitudinal strain was less than the strains of $\mathrm{G} 1$ and $\mathrm{G} 2$.

The applied load versus the strain relationships of the top, mid-height, and bottom reinforcements at the center of the girders are shown in Fig. 24. The maximum tensile strains occurred at the bottom rebar, while compressive strains occurred at the top rebar. The tensile strain was measured at the mid-height rebar, located $75 \mathrm{~cm}$ from the bottom surface, indicating that the neutral axis location is above the midheight of the girder. Compressive and tensile strains of approximately 0.0006 and 0.0012 , respectively, were measured from the top and bottom rebars, respectively, when the maximum load was applied. G1 and G2 showed non-linear behavior at a load $2700 \mathrm{kN}$ with tensile strains of 0.0061 and 0.0075 , respectively. The nonlinear behavior can be attributed to the increased stress absorption by the rebars due to the cracking of the concrete. The comparison of the overall strains of the reinforcements showed that strains of G1 and G2 were similar, indicating that the stress transfer through the cross beam occurred properly and that the girders, cross beams, and deck continuity remained intact throughout the experiment, resulting in coherent strain behavior in G1 and G2.

\subsection{Neutral Axis Behavior}

Based on the longitudinal strain measured from G1 at the center span for various depth increments, the neutral axis locations for various load increments are shown in Fig. 25. As shown in the figure, the initial location of the neutral axis of $\mathrm{G} 1$ at the center span of the curved bridge was $90 \mathrm{~cm}$ from the bottom surface. The neutral axis shifted up to $105 \mathrm{~cm}$ when the maximum load was applied due to the flexural stiffness reduction from the tensile cracking of the girder. Although initial transverse tension cracking occurred at the bottom section of $\mathrm{G} 1$ at the center span under a load of $1400 \mathrm{kN}$, the neutral axis location remained unchanged until G1 and G2 reached load of 2100 and $1900 \mathrm{kN}$, respectively. The delay in the neutral axis movement indicated that a significant flexural stiffness reduction in the girder is required to affect its macro-structural behavior, such as a change of the neutral axis location. Also, this behavior

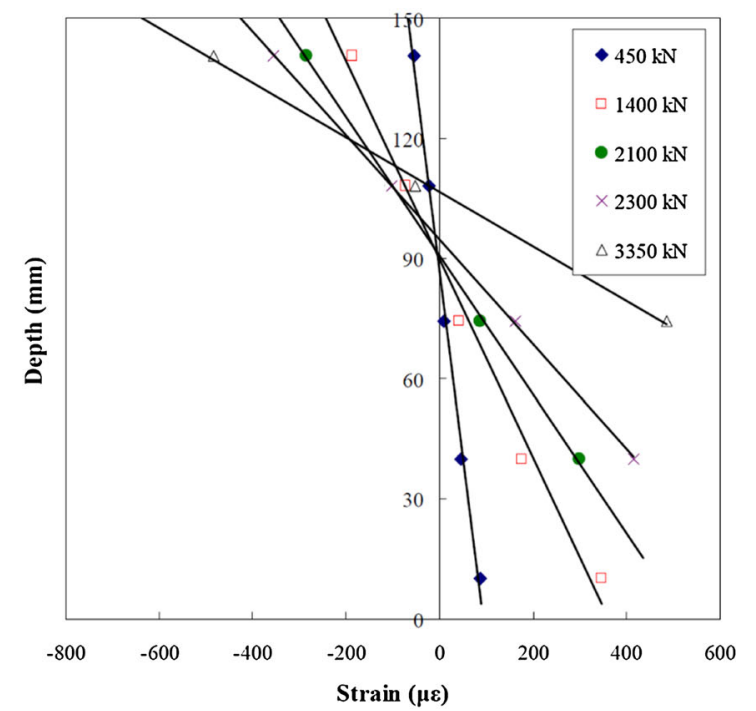

(a)

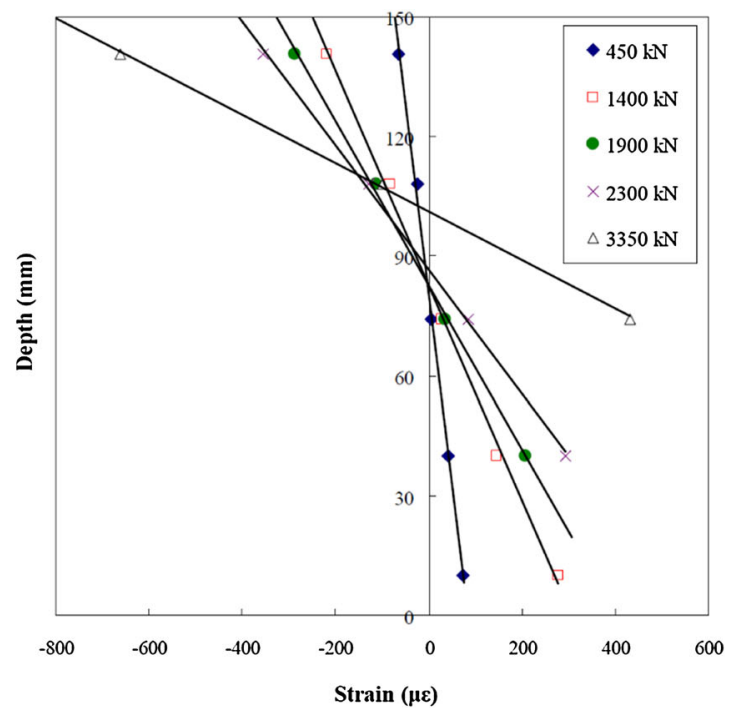

(b)

Fig. 25 Location of the neutral axis under various loads: a G1 girder, b G2 girder. 


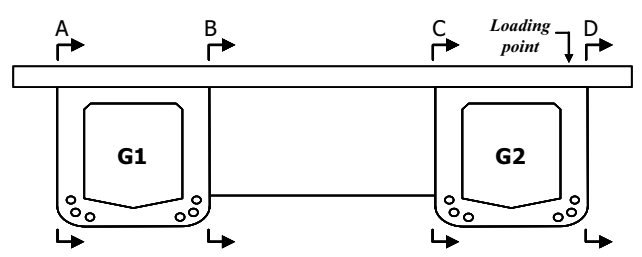

G1 A

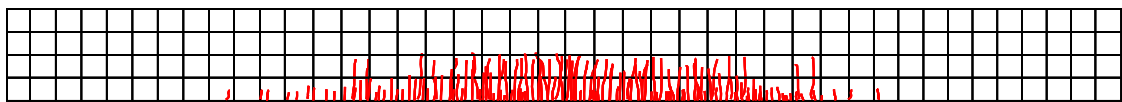

G1 B
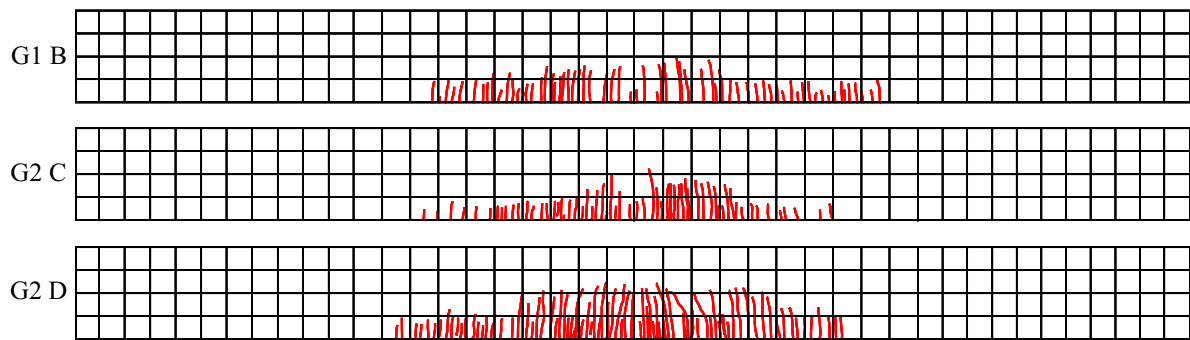

Fig. 26 Crack patterns.

indicated that the overall serviceability of the PSC curved girders can be guaranteed in the service state.

\subsection{Crack Pattern}

The crack patterns monitored during the test of the bridge are shown in Fig. 26. The cracks were marked at a load interval of $200 \mathrm{kN}$ after the initial cracking load. Initial cracking started at the bottom section of G2 at the center span under a load of $1400 \mathrm{kN}$. As shown in Fig. 26, transverse cracks were concentrated around the center span where the load point is located. As the load increased, the crack formation pattern widened toward the supports. The crack dispersion region was wider on the outer surface than on the inner surface of G1. Also, the cracked region was wider in G1 than in G2, which can be attributed to the longer girder lengths of G1 than G2 and G1-A than G1-B. The cracks of G2-D were concentrated around the load point location with a cracking region width nearly equivalent to that of G1-A due to the concentrated stresses from the concentrated applied load. The girder surfaces in contact with the cross

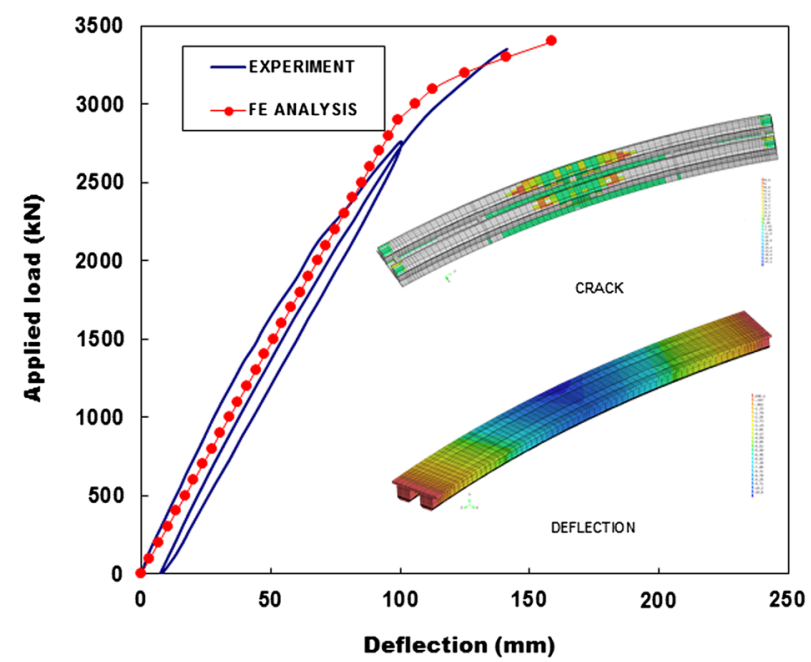

Fig. 27 Comparison of experiment and FEM simulation results. beams (G1-B and G2-C) had fewer cracks due to the stress distribution mechanism of the cross beams.

\section{Comparison of Simulation and Test Results}

The static load versus mid-span deflection relationships obtained from the experiment and the simulation are compared in Fig. 27. As shown in the figure, the elastic stiffness from the simulation was slightly less than that from the experiment, which can be attributed to the loading eccentricity, inexact bridge symmetry, and minor support misplacement induced in the experiment. However, the overall behaviors from the simulation and experiment were very similar. According to an FEM simulation and the experiment, the maximum loads and deflections were $3600 \mathrm{kN}$ and $200.46 \mathrm{~mm}$ and $3400 \mathrm{kN}$ and $141.2 \mathrm{~mm}$, respectively. The difference between the maximum loads and deflections from the experiment and the simulation were $200 \mathrm{kN}$ and $59.26 \mathrm{~mm}$, respectively, with the simulation results being larger. The differences stemmed from the pre-setting of the maximum applied load in the experiment at $3400 \mathrm{kN}$ to maintain test safety. The test specimen did not reach complete failure at the maximum load, but the overall structural behaviors from the experiment and simulation were similar, indirectly verifying the safety and serviceability of the precast PSC curved girder bridge.

\section{Conclusions}

The structural performance of a precast PSC curved girder bridge constructed using a curvature-and-dimension-adjustable recyclable formwork called the Multi-tasking formwork is evaluated. A FEM simulation and a full-scale experiment were conducted on a $40 \mathrm{~m}$ two-girder curved bridge built using the Multi-tasking formwork. For the design of the girder and bridge, various design parameters were considered. Based on the study results obtained from 
the static bending test as part of the experiment and the simulation, the following conclusions can be drawn.

1. Cost-efficient precast PSC curved girders can be constructed using the newly developed Multi-tasking formwork with curvature, height, end angles, and length-adjustable mechanisms.

2. A preliminary design of a precast PSC curved girder bridge was performed using nonlinear FEM simulations by varying the PS force and cross-sectional area of the outer and inner girders as well as the number of girders and the load point location. The design results showed that varying the PS force in the inner and outer girders enhanced the stability of the curved bridge.

3. The simulation results of a single curved girder showed that a smaller radius of curvature caused torsional stability problems. However, as an integrated bridge system, the stability problem was eliminated by efficient stress transfer through the cross beams.

4. The static loading test of the precast PSC curved girder bridge showed that the initial cracks occurred at a load of $1400 \mathrm{kN}$, which was three times the design load. The maximum allowable deflection of $50 \mathrm{~mm}$ was reached at a load of $1800 \mathrm{kN}$, which was four times the design load and 1.3 times the initial cracking load, verifying the safety and serviceability of the precast PSC curved girder bridge in a service state.

5. Two girders connected by the RC cross beams and the deck showed similar deflection and strain patterns, which can be attributed to stable stress transfer through the cross beams.

6. The FEM simulation and full-scale experimental results were similar. The experiment was stopped at a preset maximum load of $3400 \mathrm{kN}$ out of safety concerns, but the similarity of the two results indirectly verified the safety and serviceability of the bridge, even in an extreme failure state.

\section{Acknowledgments}

This work was partially supported by a grant from the National Research Foundation of Korea (NRF) funded by the Korean government (MSIP) (No. 2011-0030040). This work was also partially supported by the R\&D Policy Infrastructure Technology Commercialization Project titled "Commercialization Research of Precast curved PSC Beam Constructed using Smart Mold System" by the Ministry of Land, Transport, and Maritime Affairs of the Korean government. The authors wish to express their gratitude for this financial support. The opinions, findings, and conclusions of the paper are those of the authors and do not necessarily reflect the views of the sponsors.

\section{Open Access}

This article is distributed under the terms of the Creative Commons Attribution 4.0 International License (http:// creativecommons.org/licenses/by/4.0/), which permits unrestricted use, distribution, and reproduction in any medium, provided you give appropriate credit to the original author(s) and the source, provide a link to the Creative Commons license, and indicate if changes were made.

\section{References}

Amorn, W., Tuan, C. Y., \& Tadros, M. K. (2008). Curved, precast, pretensioned concrete I-girder bridges. PCI Journal, 53(6), 48-66.

Dong, J., \& Sause, R. (2010). Behavior of hollow tubular-flange girder systems for curved bridges. Journal of Structural Engineering, 136(2), 174-182.

Lin, W., \& Yoda, T. (2010). Analysis, design and construction of curved composite girder bridges: State-of-the-art. International Journal of Steel Structures, 10(3), 207-220.

Linzell, D. G., Leon, R. T., \& Zureick, A. H. (2004). Experimental and analytical studies of a horizontally curved steel I-girder bridge during erection. Journal of Bridge Engineering, 9(6), 521-530.

Mansur, M. A., \& Rangan, B. V. (1981). Study of design methods for reinforced concrete curved beams. ACI Journal, 78(21), 226-254.

McElwain, B. A., \& Laman, J. A. (2000). Experimental verification of horizontally curved I-girder bridge behavior. Journal of Bridge Engineering, 5(4), 284-292.

Morris, D. L. (1968). Curved beam stiffness coefficients. American Society of Civil Engineering, 94, 1165-1174.

Nakai, H., \& Yoo, C. H. (1988). Analysis and design of horizontally curved steel bridges. New York, NY: McGraw-Hill.

Schmitt, W. (1966). "Interchange utilizes arcwelded horizontally curved span." unpublished paper submitted to Lincoln Arc Welding Foundation.

Sennah, K. M., \& Kennedy, J. B. (2001). Sate-of the-art in design of curved box-girder bridges. Journal of Bridge Engineering, 6(3), 159-167.

Spyropoulos, P. J. (1963). Circularly curved beams transversely loaded. ACI Journal, 60(10), 1457-1468.

Suros, O., \& Chu, H. Y. (1991). Reducing airport congestion. Modern Steel Construction, 31(6), 21-25.

Takoya, C., \& Willaims, E. B. (2003). Development of computational software for analysis of curved girder under construction loads. Computer and Structures, 81(21), 2087-2098.

Vlasov, V. Z. (1946). Thin-walled elastic beam. Washington, D.C: National Science Foundation.

Yoo, C. H., Donald, R. E., \& Conrad, P. H. (1974). Non-prismatic curved girder analysis. Computer and Structures, 4(3), 675-698.

Zhang, H. L., Huang, D. Z., \& Wang, T. L. (2005). Lateral load distribution in curved steel I-bridges. Journal of Bridge Engineering, 10(3), 281-290.

Zureick, A., \& Naqib, R. (1999). Horizontally curved steel I-girders state-of-the-art analysis methods. Journal of Bridge Engineering, 4(1), 38-47. 